\title{
Intranasal wnt3a Attenuates Neuronal Apoptosis through Frz1/PIWIL1a/FOXM1 Pathway in MCAO Rats
}

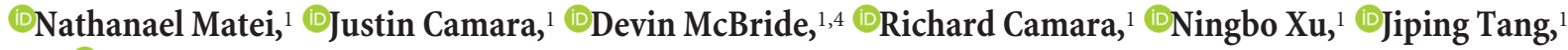 \\ and $\odot$ John H. Zhang ${ }^{1,2,3}$ \\ Departments of ${ }^{1}$ Physiology and Pharmacology, ${ }^{2}$ Anesthesiology, ${ }^{3}$ Neurosurgery, Loma Linda University, Loma Linda, California 92354 , and ${ }^{4}$ Vivian L. \\ Smith Department of Neurosurgery, McGovern Medical School, University of Texas Health Science Center at Houston, Houston, Texas 77030
}

After ischemic stroke, apoptosis of neurons is a primary factor in determining outcome. Wnt3a is a naturally occurring protein that has been shown to have protective effects in the brain for traumatic brain injury. Although wnt3a has been investigated in the phenomena of neurogenesis, anti-apoptosis, and anti-inflammation, it has never been investigated as a therapy for stroke. We hypothesized that the potential neuroprotective agent wnt3a would reduce infarction and improve behavior following ischemic stroke by attenuating neuronal apoptosis and promoting cell survival through the Frizzled-1/PIWI1a/FOXM1 pathway in middle cerebral artery occlusion (MCA0) rats. A total of 229 Sprague Dawley rats were assigned to male, female, and 9-month-old male MCA0 or sham groups followed by reperfusion $2 \mathrm{~h}$ after MCA0. Animals assigned to MCAO were either given wnt3a or its control. To explore the downstream signaling of wnt3a, the following interventions were given: Frizzled-1 siRNA, PIWI1a siRNA, and PIWI1a-clustered regularly interspaced short palindromic repeats, along with the appropriate controls. Post-MCAO assessments included neurobehavioral tests, infarct volume, Western blot, and immunohistochemistry. Endogenous levels of wnt3a and Frizzled-1/PIWI1a/FOXM1 were lowered after MCAO. The administration of intranasal wnt3a, $1 \mathrm{~h}$ after MCA0, increased PIWIL1a and FOXM1 expression through Frizzled-1, reducing brain infarction and neurological deficits at 24 and $72 \mathrm{~h}$. Frizzled- 1 and PIWIla siRNAs reversed the protective effects of wnt3a after MCAO. Restoration of PIWI1a after knockdown of Frizzled-1 increased FOXM1 survival protein and reduced cleaved caspase-3 levels. In summary, wnt3a decreases neuronal apoptosis and improves neurological deficits through Frizzled-1/PIWI1a/FOXM1 pathway after MCAO in rats. Therefore, wnt3a is a novel intranasal approach to decrease apoptosis after stroke.

Key words: FOXM1; Frizzled-1; MCA0; PIWI1a; stroke; wnt3a

\section{Significance Statement}

Only $5 \%$ of patients receive recombinant tissue plasminogen activator after stroke, and few qualify for mechanical thrombectomy. No neuroprotective agents have been successfully translated to promote neuronal survival in stroke. Thus, using a clinically relevant rat model of stroke, middle cerebral artery occlusion, we explored a novel intranasal administration of wnt3a. wnt3a naturally occurs in the body and crosses the blood-brain barrier, supporting the clinically translatable approach of intranasal administration. Significant neuronal apoptosis occurs during stroke, and wnt3a shows promise due to its antiapoptotic effects. We investigated whether wnt3a mediates its poststroke effects via Frizzled-1 and the impact on its downstream signaling molecules, PIWI1a and FOXM1, in apoptosis. Elucidating the mechanism of wnt3a will identify additional pharmacological targets and further understanding of stroke.

\section{Introduction}

Stroke is an acute onset disturbance of cerebral function due to ischemia or hemorrhage. Ischemic stroke is the third leading

\footnotetext{
Received Aug. 19, 2017; revised March 27, 2018; accepted April 4, 2018.

Author contributions: N.M., D.M., J.T., and J.H.Z. designed research; N.M., D.M., and N.X. performed research;

N.M., J.C., and R.C. analyzed data; N.M., J.C., D.M., R.C., and J.H.Z. wrote the paper.

This work was supported by National Institutes of Health Grant NS081740 to J.H.Z.

The authors declare no competing financial interests.

Correspondence should be addressed to Dr. John H. Zhang, Departments of Anesthesiology and Physiology, Loma Linda University School of Medicine, Risley Hall, Room 219, 11041 Campus Street, Loma Linda, CA 92354. E-mail: Johnzhang3910@yahoo.com.
}

cause of mortality globally and the number 1 cause of disability (Mackay and Mensah, 2004). Two approaches have been pursued to reduce the disease burden of stroke: neuroprotection and reperfusion (Fisher and Brott, 2003). Of these two, only reperfusion has had success in human clinical trials in the form of pharmacological recombinant tissue plasminogen activator intervention and mechanical clot disruption (Rha and Saver, 2007). Recombinant tissue plasminogen activator continues to be the only FDA- 
approved pharmacological intervention approved for acute ischemic stroke despite multiple clinical trials exploring alternative treatments (Roth, 2011). Thus, we evaluated the potential neuroprotective agent wnt3a to protect against neuronal damage caused by ischemic stroke.

wnt3a is a glycolipoprotein that controls important cellular functions, including apoptosis, neurogenesis, embryonic development, adult homeostasis, and cell polarity (MacDonald et al., 2009; Zhang et al., 2011; Wu et al., 2014). Nineteen different isoforms of "wnt" all bind to the N-terminal extracellular cysteine-rich domain of Frizzled (Frz) family receptor, a serpentine G-protein receptor (Rao and Kühl, 2010), which has its own specific isoforms. Each wnt isoform has specific innate functions dependent in part on cell type. For example, in dendritic cells, the wnt3a isoform upregulates VEGF, whereas the wnt5a isoform induces IL-10 through alternative pathways (Oderup et al., 2013). Although the wnt pathway has been studied extensively, the identification of new isoforms of wnt and their unique mechanistic endpoints have revived therapeutic interest in wnt (Cerpa et al., 2009; Shruster et al., 2012; Inestrosa and Varela-Nallar, 2014).

Recent studies have targeted GSK-3 $\beta$ reduction to improve outcomes after ischemic stroke. In the diabetic ischemic stroke rat model, insulin, an inhibitor of the activation of GSK-3 $\beta$ (Cohen and Goedert, 2004), and TDZD-8, a selective inhibitor of GSK-3 $\beta$, both reduced the severity of the deleterious consequences of stroke: reducing the infarct volume and lowering the expression of GSK-3 $\beta$ (Collino et al., 2009). Convincingly establishing a role for GSK $3 \beta$ in stroke pathology, Kelly et al. (2004) showed that inhibition of GSK $3 \beta$ with CXhir025 in both OGD in vitro and in vivo rat middle cerebral artery occlusion (MCAO) models increased neuronal cell survival. In the intracerebral hemorrhage mouse model, 6-bromoindirubin- $3^{\prime}$-oxime, a selective GSK-3 $\beta$ inhibitor, acutely administered, reduced hematoma volume by attenuating the expression of GSK-3 $\beta$ phosphorylation/activation, which increased the viability of neurons and other cell types (Zhao et al., 2017). These findings suggest that the wnt/GSK-3 $\beta$ / $\beta$-catenin pathway may be further explored for treatment in the pathology of stroke.

In this study, the novel glycolipoprotein wnt3a is used for the very first time as an intranasal (iN) therapy to influence the pathophysiology of stroke in the MCAO model. Other studies of wnt3a have found that it prevents apoptosis (Reeves et al., 2012) and is neuroprotective, but the mechanistic understanding is limited. Researchers showed that PIWL1a (Reeves et al., 2012) directly affects the regulation of $\beta$-catenin in a cell-survival path- way in lung cancer cells, but further research is needed to establish the relationship between PIWI1a and wnt3a in stroke. Reports have linked $\beta$-catenin with FOXM1 (Zhang et al., 2011), and both have been linked to the inhibition of apoptosis (Jiang et al., 2014).

To date, there are 10 human G-protein-coupled Frz receptors, but only Frz1 has been supported in the literature to be activated by the binding of wnt3a (Chacón et al., 2008; Oderup et al., 2013; Wu et al., 2014; Arrázola et al., 2015; R\&D Systems, 2018). Although wnt3a is known to bind to Frz1, the intracellular pathway triggered within neurons remains poorly investigated. In the present study, we hypothesize the effect of iN wnt3a on its downstream targets, Frz1/PIWI1a/FOXM1, will attenuate neuronal apoptosis in the rat model of transient MCAO. (Fig. 1). 


\section{Materials and Methods}

Animals. All experiments were approved by the Institutional Animal Care and Use Committee of Loma Linda University, complied with the National Institutes of Health's Guide for the care and use of laboratory animals, and are reported according to the ARRIVE (Animal Research: Reporting of In Vivo Experiments) guidelines. Animals were housed in a $12 \mathrm{~h}$ light/dark cycle, temperature-controlled room. Animals were divided into groups in a randomized fashion, and experiments were performed in a blinded manner.

Laboratory animals. Adult male (weighing 250-300 g), aged male (weighing $400 \mathrm{~g}$ at 9 months of age), female (weighing 240-250 g) Sprague Dawley rats were used in the proposed study.

Experimental design. A total of 229 rats were used.

Experiment 1 characterized the endogenous time course of wnt $3 a$, Frz1, PIWI1a, p-GSK3 $\beta$, FOXM1, and cleaved caspase-3 (CC-3) in the right hemisphere at 6, 12, 24, and $72 \mathrm{~h}$ after MCAO. Twenty-six rats were used in the following groups: $\operatorname{sham}(n=4), 6 \mathrm{~h}(n=5), 12 \mathrm{~h}(n=6), 24 \mathrm{~h}$ $(n=6)$, and $72 \mathrm{~h}(n=5)$.

Experiment 2 evaluated the role of wnt3a in the pathophysiology of MCAO as follows. First, we tested the effect of iN wnt3a. A total of 203 rats were used in the following groups: $24 \mathrm{~h}$ endpoints: sham $(n=11)$, $\mathrm{MCAO}+$ vehicle $(n=14), \mathrm{MCAO}+$ wnt3a low dose $(\mathrm{LD} ; 0.4 \mu \mathrm{g} / \mathrm{kg})$ $(n=8), \mathrm{MCAO}+$ wnt3a high dose (HD; $1.2 \mu \mathrm{g} / \mathrm{kg})(n=13), \mathrm{MCAO}+$ wnt3a + scrambled siRNA $(n=7)$, MCAO + wnta3a + Frz1-siRNA $(n=8), \mathrm{MCAO}+$ wnt3a + PIWI-siRNA $(n=8), \mathrm{MCAO}+$ wnt3a + scrambled clustered regularly interspaced short palindromic repeats (CRISPR; $n=7)$, MCAO + wnt3a + PIWI CRISPR + Frz1-siRNA $(n=$ 7); female: sham $(n=6), \mathrm{MCAO}+$ vehicle $(n=8), \mathrm{MCAO}+$ wnt3a HD $(1.2 \mu \mathrm{g} / \mathrm{kg})(n=8)$; aged rats: sham $(n=6), \mathrm{MCAO}+$ vehicle $(n=7)$, $\mathrm{MCAO}+$ wnt3a HD $(1.2 \mu \mathrm{g} / \mathrm{kg})(n=6)$; permanent MCAO (pMCAO): MCAO + vehicle $(n=10)$, MCAO + wnt3a HD $(1.2 \mu \mathrm{g} / \mathrm{kg})(n=9)$; Naive groups: Naive $(n=6)$, Naive + scrambled siRNA $(n=12)$, Naive + Frz1-siRNA $(n=6)$, Naive + PIWI-siRNA $(n=6)$, Naive + PIWIla CRISPR + Frz-1 siRNA $(n=6) ; 72$ h endpoints: Sham $(n=6)$, MCAO + vehicle $(n=8), \mathrm{MCAO}+$ wnt3a HD $(n=8)$. Recombinant mouse wnt3a (Abcam; ab81484), used for all molecular and behavioral studies, and human GST tagged wnt3a (Abcam; 153563), only used in Figure 13 to confirm the presence and delivery, were reconstituted in $\mathrm{ddH}_{2} \mathrm{O}$ to yield $0.1 \mathrm{mg} / \mathrm{ml}$ and given at $0.4 \mu \mathrm{g} / \mathrm{kg}$ for the LD or $1.2 \mu \mathrm{g} / \mathrm{kg}$ for the HD. A total of 500 pmol of Frz1 (sc-39977 and AM16708) and PIWI1a (sc40677 and AM16708) was dissolved in $2 \mu \mathrm{l}$ of sterilized water and injected intracerebroventricularly $24 \mathrm{~h}$ before MCAO. The same volume of scramble siRNA (sc-37007 and AM4611) was administered as control. For PIWIla-CRISPR activation, $2 \mu \mathrm{g}$ of in $2 \mu \mathrm{l}$ (transfection medium and transfection reagent, described in Intracerebroventricular injection) per animal was injected $24 \mathrm{~h}$ before MCAO (detailed in Intracerebroventricular injection). The control of a scrambled CRISPR was used with the same volume.

MCAO model. Rats were anesthetized intraperitoneally with a mixture of ketamine $(80 \mathrm{mg} / \mathrm{kg})$ and xylazine $(20 \mathrm{mg} / \mathrm{kg})$, until no pinch-paw reflex was observed, and maintained throughout the experiments. Body temperature and respiration rate were monitored perioperatively. A vertical midline cervical incision was made, and the right common carotid artery was exposed and dissected. All branches of the external carotid artery were isolated, coagulated, and transected, and then the external carotid artery was divided (leaving 3-4 $\mathrm{mm}$ ). The internal carotid artery was isolated, and the pterygopalatine artery was ligated close to its origin. A $5 \mathrm{~mm}$ aneurysm clip was used to clamp the common carotid artery. The external carotid artery stump was reopened, and a 4.0 monofilament nylon suture with an enlarged, round tip was inserted through the internal carotid artery; insertion was stopped when resistance was felt, occluding the origin of the right MCA. After $2 \mathrm{~h}$ of occlusion, the suture was withdrawn to allow for reperfusion. The external carotid artery was ligated, and the aneurysm clip was removed. The skin was sutured (1\% lidocaine was applied), and the animal was allowed to recover. Sham surgery included the exposure of the common, external, and internal carotid arteries with all ligations and transections; no occlusion occurred in the sham group (Kusaka et al., 2004; Chen et al., 2011).
Intracerebroventricular injection. As described previously (Liu et al., 2007; Chen et al., 2013), rats were anesthetized with isoflurane (4\% induction, $2.5 \%$ maintenance) and mounted on a stereotaxic frame. The needle of a $10 \mu \mathrm{l}$ Hamilton syringe was inserted through a burr hole perforated through the skull into the left lateral ventricle using the following coordinates relative to bregma: $1.5 \mathrm{~mm}$ posterior, $1.0 \mathrm{~mm}$ lateral, and $3.2 \mathrm{~mm}$ below the horizontal plane of the bregma. siRNA was injected $24 \mathrm{~h}$ before MCAO. According to the manufacturer's instructions, a total volume of $2 \mu \mathrm{l}(500 \mathrm{pmol})$ of siRNA in sterile saline was injected in ipsilateral ventricle at a rate of $0.5 \mu \mathrm{l} / \mathrm{min}$. A combination of two siRNAs were used for Frz1 (sc-39977 and AM16708) and PIWI1a (sc-40677 and AM16708) providing advantages in both potency and specificity of gene silencing. The same volume of scramble siRNA (sc-37007 and AM4611) was used as a negative control. siRNA is a tool that induces short-term silencing of protein coding genes and targets a specific mRNA for degradation. To reverse the effects of siRNA, we will use an engineered form of CRISPR-associated (Cas) protein system (Jinek et al., 2012). Briefly, in this system, the Type II CRISPR protein Cas9 is directed to genomic target sites by short RNAs, where it functions as a endonuclease, which can inactivate or activate genes (Perez-Pinera et al., 2013), used successfully in plants and animals, both vertebrae and invertebrae (Horvath and Barrangou, 2010; Gratz et al., 2013; Jiang et al., 2013; Mali et al., 2013; Bortesi and Fischer, 2015). CRISPR will be used to activate PIWI1a expression in the rat brain. A total of $4 \mu \mathrm{l}$ of active PIWIla CRISPR (sc418611) was injected $24 \mathrm{~h}$ before MCAO; $20 \mu \mathrm{g}$ of CRISPR was suspended in $20 \mu \mathrm{l}$ of plasmid transfection medium (sc-108062) and activated with another $20 \mu$ l of transfection reagent (sc-395739), totaling 2 $\mu \mathrm{g}$ per animal of active CRISPR. The control scrambled CRISPR (sc437275 ) followed the same steps, and a total of $2 \mu \mathrm{g}$ per animal was given intracerebroventricularly. To prevent possible leakage, the needle was kept in situ for an additional $10 \mathrm{~min}$ after completing the injection and then withdrawn slowly over $5 \mathrm{~min}$. After removal of the needle, the burr hole was sealed with bone wax, the incision was sutured, and the rats were allowed to recover.

2,3,5-Triphenyltetraolium chloride staining. As described previously (Hu et al., 2009), 2,3,5-triphenyltetrazolium chloride monohydrate staining was performed to determine the infarct volume at 24 and $72 \mathrm{~h}$ after MCAO. The possible interference of brain edema with infarct volume was corrected (whole contralateral hemisphere volume minus nonischemic ipsilateral hemisphere volume) and the infarcted volume was expressed as a percentage of the whole contralateral hemisphere (McBride et al., 2016).

Immunofluorescence staining. Immunohistochemistry was performed as described previously (Chen et al., 2013). Briefly, rats were perfused with cold PBS under deep anesthesia, followed by infusion of $4 \%$ formalin $24 \mathrm{~h}$ after MCAO. The brains were harvested and immersed in $4 \%$ formalin at $4^{\circ} \mathrm{C}$, then dehydrated with $30 \%$ sucrose for $7 \mathrm{~d}$, then mounted in OCT and frozen. After cryosectioning into $10-\mu \mathrm{m}$-thick sections, slices were incubated with the primary antibodies goat anti-Frz1 (1:100) (PA547072, RRID:AB_2610121), rabbit anti-NeuN (1:200) (ab177487, RRID: AB_2532109), rabbit anti-GFAP (1:100) (ab16997, RRID:AB_443592), goat anti-ionized calcium binding adaptor molecule 1 (IBA1, 1:200; ab107159, RRID:AB_10972670), followed by incubation with appropriate secondary antibodies conjugated with either FITC (Neun, GFAP, Iba1) or Rodamine Red (Frz1) and DAPI (nuclear marker, color blue) (Jackson ImmunoResearch Laboratories). Negative control staining was performed by omitting the primary antibody. The sections were visualized with a fluorescence microscope (Leica Microsystems).

Western blots. Western blotting was performed as described previously (Ayer et al., 2012; Chen et al., 2013). At each time point, rats were perfused with cold PBS, pH 7.4, solution delivered via intracardiac injection, followed by dissection of the brain into right frontal, left frontal, right parietal, left parietal, cerebellum, and brainstem. The brain parts were snap frozen in liquid nitrogen and stored at $-80^{\circ} \mathrm{C}$ for subsequent analysis. Right hemisphere protein extraction from whole-cell lysates were obtained by gently homogenizing the hemisphere in RIPA lysis buffer (Santa Cruz Biotechnology) with further centrifugation at $14,000 \times g$ at $4^{\circ} \mathrm{C}$ for $30 \mathrm{~min}$. The supernatant was used as whole-cell protein extract, and the protein concentration was determined using a detergentcompatible assay (Bio-Rad). Equal amounts of protein were loaded on an 

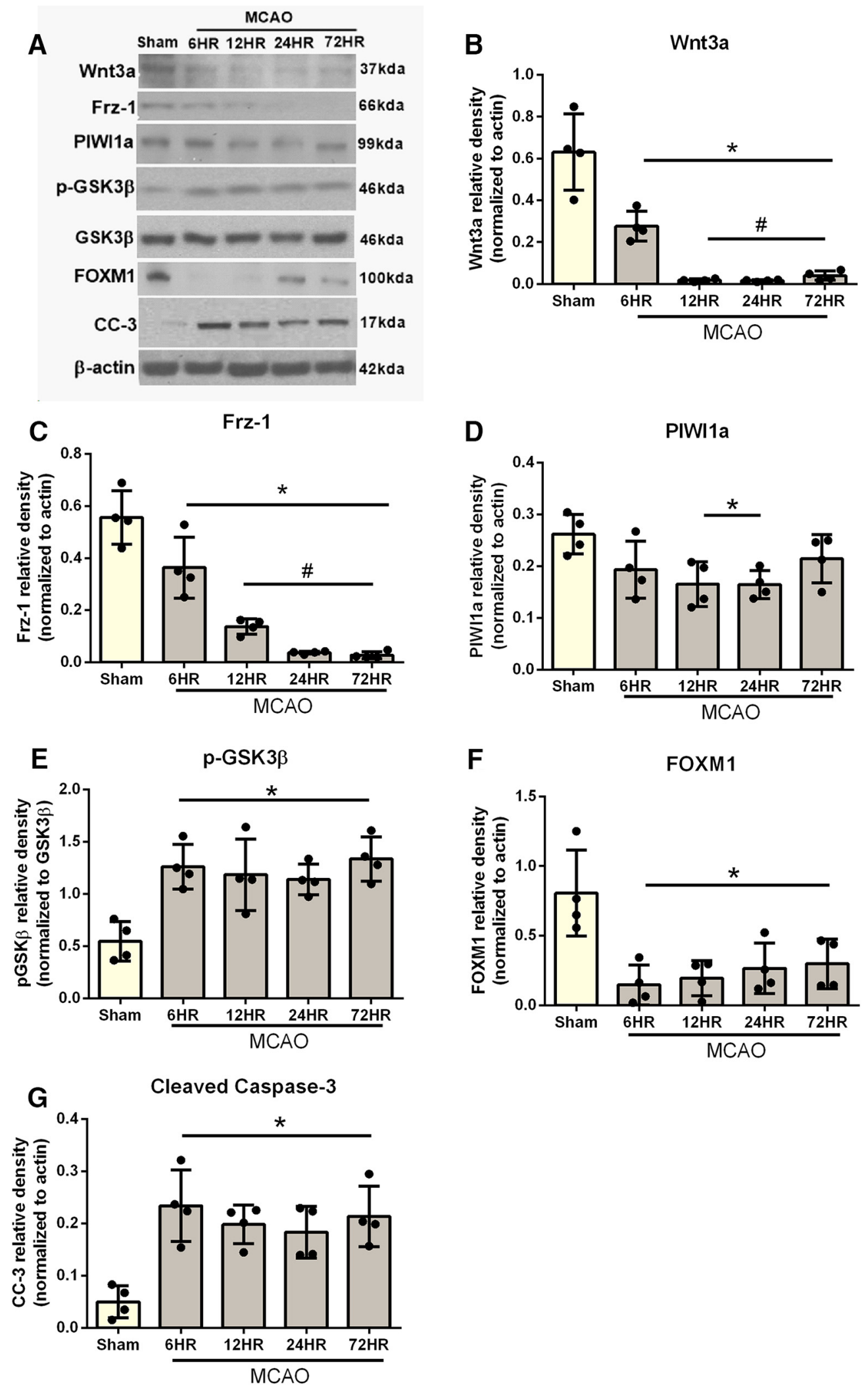

Figure 2. Time course of wnt3a, Frz1, PIWI1a, pGsk-3 $\beta$, FOXM1, and CC-3 in the right hemisphere of the rat brain after MCA0.A, Representative Western blots. Quantitative analysis with Western blot showed that the expression of $(\boldsymbol{B})$ wnt3a and $(\boldsymbol{C})$ Frz1 significantly decreased by $6 \mathrm{~h}$. D. PIWl1a was decreased by $12 \mathrm{~h}$ and returned to sham levels by $72 \mathrm{~h}$. $\boldsymbol{E}$, However, pGsk-3 $\beta$ was increased after MCA0. F, FOXM1 was decreased after MCA0, but (G) C(-3 was increased. Each column represents the mean \pm SD ( $n=4 /$ group). ${ }^{*} p<0.05$ versus Sham. ${ }^{\#} p<0.05$ versus 6 h. Figure $2-1$ (available at https://doi.org/10.1523/JNEUROSCI.2352-17.2018.f2-1) reports the specific statistics for each group comparison. 
A

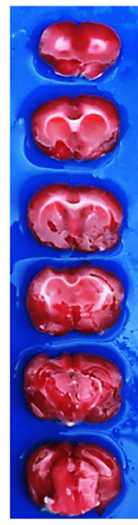

Sham

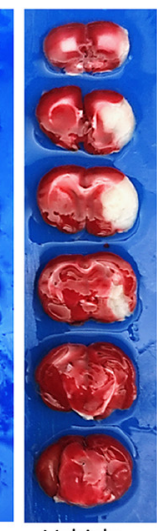

Vehicle

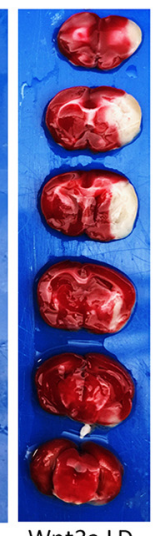

Wnt3a LD

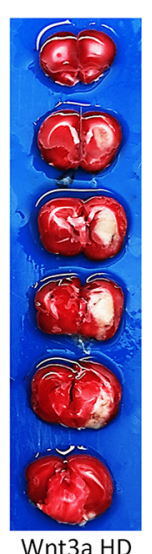

B

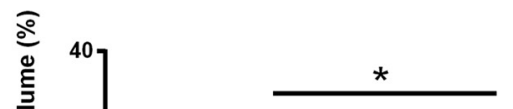
ํㅗㅇ 30

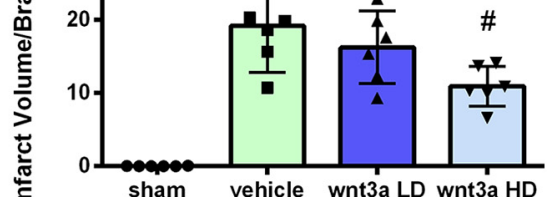

$\mathrm{MCAO}$
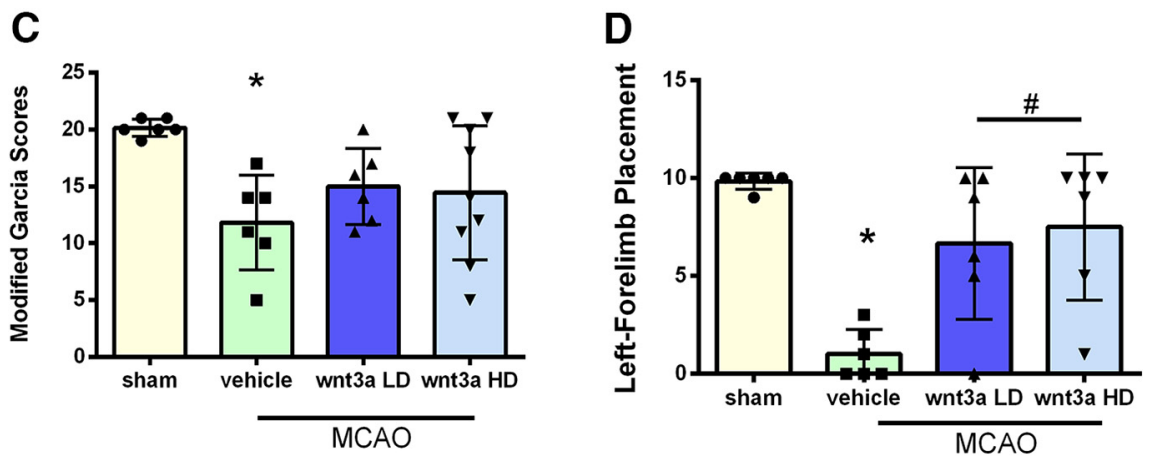

Figure 3. wnt3a attenuated infarct volume and improved neurological function $24 \mathrm{~h}$ after MCAO. $\boldsymbol{A}$, Representative triphenyltetrazolium chloride (TTC) staining images of coronal sections. $\boldsymbol{B}$, wnt3a HD $(1.2 \mu \mathrm{g} / \mathrm{kg})$ effectively reduced the infarct volume. $\boldsymbol{C}$, Modified Garcia scores showed that LD and HD of wnt3a decreased neurological deficits. $\boldsymbol{D}$, Left forelimb placement was improved in both the LD and HD of wnt3a. Each column represents the mean $\pm S D\left(n=6-9 /\right.$ group). ${ }^{*} p<0.05$ versus Sham. ${ }^{\#} p<0.05$ versus vehicle.

SDS-PAGE gel. After being electrophoresed and transferred to a nitrocellulose membrane, the membrane was blocked and incubated with the primary antibody overnight at $4^{\circ} \mathrm{C}$. The primary antibodies were rabbit polyclonal anti-wnt3a (1:1000; ab28472, RRID:AB_2215308), rabbit polyclonal anti-Frzl (1:1000; ab126262, RRID:AB_11128657), rabbit polyclonal antiPIWI1a (1:1000; ab12337, RRID:AB_470241), mouse monoclonal anti- $\beta$-catenin (1:1000; ab32572, RRID:AB_725966), rabbit polyclonal anti-pGsk-3 $\beta$ (1:1000; ab75745, RRID:AB_1310290), rabbit polyclonal anti-FOXM1 (1:1000; sc-376471, RRID:AB_11150135), rabbit polyclonal anti-CC-3 (1:1000; ab13847, RRID:AB_443014), rabbit polyclonal anti-GST (ab19256, RRID:AB_444809), rabbit monoclonal anti-lipoprotein receptor-related protein-6 (LRP6) (1:1000; ab134146), and rabbit polyclonal anti-phospho-LRP6 (1:500; 2568s, RRID:AB_2139327). For loading control, the same membranes were blotted with primary antibody of goat anti- $\beta$ actin (1:1000; sc-1616, RRID:AB_630836). Nitrocellulose membranes were incubated with appropriate secondary antibodies (1:2000; Santa Cruz Biotechnology) for $30 \mathrm{~min}$ at room temperature. Immunoblot bands were further probed with a chemiluminescence reagent kit (ECL Plus; GE Healthcare). Data were analyzed by blinded researchers using ImageJ software, and each protein was normalized to their respective $\beta$-actin bands.

Neurobehavioral testing. Neurobehavioral outcomes were assessed by a blinded observer at 24 and $72 \mathrm{~h}$ after MCAO using the modified Garcia Score (Kusaka et al., 2004; Chen et al., 2010). Animal scores for sensorimotor functions evaluated six parameters: spontaneous activity, symmetry in the movement of all four limbs, forepaw outstretching, climbing, body proprioception, and response to vibrissae touch. A maximum score of 21 was given with higher scores indicating better performance.

Left forelimb testing. Vibrissae-evoked forelimb placing test was assessed by a blinded observer at 24 and $72 \mathrm{~h}$ after MCAO. Left forelimb testing assesses for asymmetry in the sensorimotor cortex and striatum.

The experimenter holds the animal so that all four limbs hang freely, and the vibrissae are stimulated by sweeping each side against the edge of a table. This elicits an ipsilateral forelimb response to place the paw on the table top. The rat is stimulated 10 times on each side, and the total number of paw placements is recorded.

Fluro-Jade-C (FJC) staining. FJC staining was performed to detect degenerating neurons with a modified FJC ready-to-dilute staining kit (Biosensis) according to the manufacturer's instructions (Schmued et al., 2005). FJC-positive neurons in a $0.56 \mathrm{~mm}^{2}$ region of the ischemic boundary zone next to the ischemic core were counted in four randomly selected microscopic fields by an independent observer. Quantified analysis was performed by blinded researchers using ImageJ software. The data were presented as the number of FJC-positive neurons in the FOV.

Statistical analysis. Quantitative data are presented as mean $\pm \mathrm{SD}$. One-way ANOVA with post hoc Tukey test was used to determine significant group differences among groups at each time point for infarction volume and Western blot data. For nonparametric data, one-way ANOVA-Wallis with Dunn's post hoc was used to analyze neurobehavioral data after deviation from normality was confirmed. $p<0.05$ was considered statistically significant. Prism 6 was used for graphing and analyzing all data (GraphPad).

\section{Results}

All sham-operated rats survived, but the overall mortality of MCAO was $21.94 \%$. The mortality was not significantly different among the experimental groups (data not shown).

\section{Endogenous expressions of wnt3a and FRZ1/PIWI1/FOXM1 were decreased in neurons $24 \mathrm{~h}$ after MCAO, while the proteins Caspase 3 and GSK3- $\beta$ were increased}

Western blot was used to detect time course expression of wnt3a, Frzd1, PIWI1a, FOXM1, pGSK-3 $\beta$, and CC-3 in brain tissue at baseline, 6, 12, 24, and $72 \mathrm{~h}$ after MCAO (Fig. 2). Representatives immunoblots are shown in Figure $2 A$. The expression pattern of wnt3a (Fig. 2B) and Frz1 (Fig. 2C) showed a significant decrease from 6 to $72 \mathrm{~h}$ after MCAO (Fig. 2B). PIWI1a was significantly decreased from 12 to $24 \mathrm{~h}$ after MCAO, but indistinguishable at $72 \mathrm{~h}$ compared with sham (Fig. 2D). After MCAO, p-GSK3 $\beta$ increased significantly from 12 to $72 \mathrm{~h}$ compared with sham (Fig. $2 E)$. Survival protein FOXM1 was significantly decreased from 6 to $72 \mathrm{~h}$ after MCAO (Fig. $2 F$ ). In contrast, apoptotic protein CC-3 was significantly increased from 6 to $72 \mathrm{~h}$ after MCAO (Fig. 2G). Figure 2-1 (available at https://doi.org/10.1523/JNEUROSCI.2352-17.2018. f2-1) reports the specific statistics for each group comparison.

\section{Effects of wnt 3a on infarction size and neurobehavioral function $24 \mathrm{~h}$ after MCAO}

Qualitative images of infarction volume in various groups are shown in Figure $3 A$; and quantitively, there was a significant reduction in infarction volume with high dosage $(1.3 \mu \mathrm{g} / \mathrm{kg})$ compared with vehicle (one-way ANOVA; Tukey's test; $n=6-9$; $F_{(3,20)}=23.44 ; p=0.0153$ ) (Fig. $3 B$ ). wnt3a restored modified Garcia (Fig. 3C) scores to sham levels and caused significant im- 
provement in left forelimb placement (Fig. 3D) compared with vehicle (one-way ANOVA; Kruskal-Wallis with Dunn's post hoc; $n=6-9 ; p=0.0031$ ) at $24 \mathrm{~h}$. With the loss of oxygen and glucose, a hypoxic state is created in the acute stage of cerebral infarction, and recanalization triggers an apoptotic neuronal stress response (Candelario-Jalil, 2009). Survival of neurons is a key contributor to outcomes after stroke (Lai et al., 2014). Thus, neuroprotection is an important therapeutic target for the treatment of stroke (Cerpa et al., 2009; Lai et al., 2014). To evaluate the effects of iN wnt3a on neurological outcomes in transient focal cerebral ischemia, infarction volume and neurobehavior were assessed.

\section{wnt 3 a reduced apoptotic cells after MCAO}

Brain coronal sections obtained $24 \mathrm{~h}$ after MCAO were stained with FJC to visualize and count degenerating cells in the penumbra of the cortex after ischemia/reperfusion (Fig. 4A). Higher levels of FJC staining were observed in the MCAO group compared with the Sham group. wnt3a significantly decreased the FJCpositive cells in the penumbra compared with vehicle $(67.00 \pm 14.24$ /field vs $193 \pm$ 30.84/field, one-way ANOVA; Tukey's test; $F_{(2,6)}=72.44 ; n=3 ; p<0.05$, for each) (Fig. 4B).

\section{Immunofluorescence of the receptor Frzl in the penumbra at $24 \mathrm{~h}$}

Staining at the edge of the infarction (Fig. $5 A)$ at $24 \mathrm{~h}$ probed neurons $(\mathrm{NeuN})$, astrocytes (GFAP), and microglia (Iba1). In the sham group, immunoreactivity of Frzl (red) was present in NeuN and GFAP, but not Iba-1 (Fig. 5B). Vehicle expression of Frz1 in Neun, GFAP, or Iba-1 could not be detected after MCAO. HD wnt3a treatment $(1.2 \mu \mathrm{g} / \mathrm{kg})$ demonstrated strong immunoreactivity of Frz1 colocalized with NeuN (Fig. 5B). Although the literature agrees with Iba-1 expression on microglial cells, our observations suggest that the expression of Frzl on Iba-1 may need to be evaluated at later time points, peaking from $72 \mathrm{~h}$ to $7 \mathrm{~d}$ after MCAO (Michalski et al., 2012; Taylor and Sansing, 2013; Kawabori et al., 2015).

\section{Effects of wnt3a on Frz1, p-GSK3 $\beta$, $\beta$-catenin, PIWI1a,} FOXM1, CC-3 pathway at 24 and $72 \mathrm{~h}$ after MCAO

Of particular interest, recent studies have shown activation of extrinsic and intrinsic pathways of caspase-mediated cell death in several forms of transient MCAO in adult rats (Ferrer and Planas, 2003). CC-3 is upregulated following MCAO, and subsequently, the inhibition of caspase- 3 reduces infarct size following transient MCAO (Ferrer and Planas, 2003). Thus, our hypothesis is that wnt3a will provide therapeutic benefits following ischemic stroke in rats via attenuation of CC-3 and prevention of neuronal apoptosis. To investigate the effects of Frzl activation with the specific HD wnt3a $(1.2 \mu \mathrm{g} / \mathrm{kg})$ agonist administered iN at $1 \mathrm{~h}$ after

\section{4 hours}

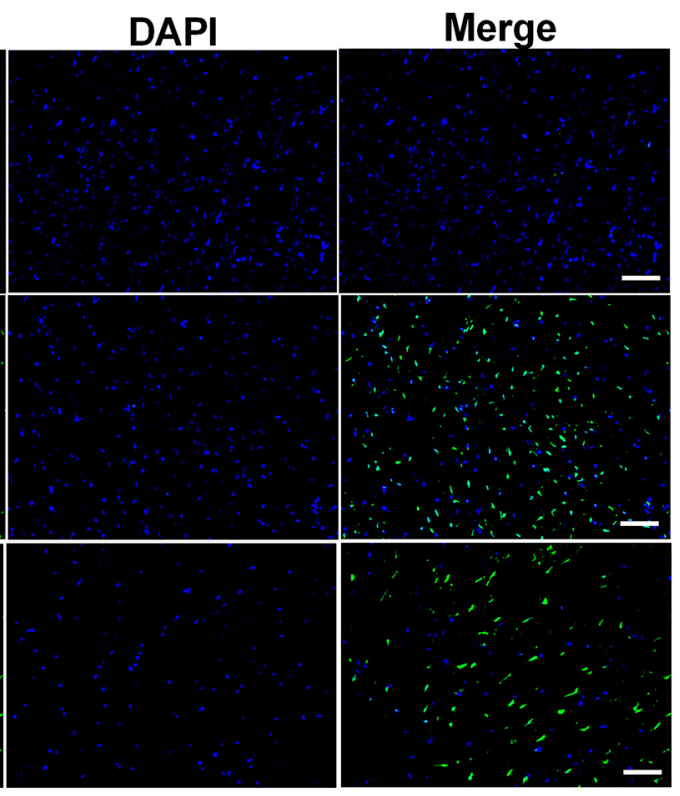

C

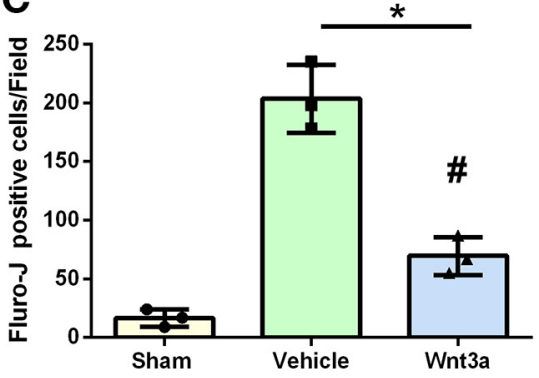

\#

Figure 4. The effects of wnt3a on neuronal damage at $24 \mathrm{~h}$ after MCAO. $A$, Representative microphotographs of FIC-positive significantly increased after MCAO induction. wnt3a significantly reduced the number of FJC-positive cells compared with vehicle $(p<0.05)$. Data are mean \pm SD. Scale bar, $50 \mu \mathrm{m} . n=3$ per group. ${ }^{*} p<0.05$ versus Sham. ${ }^{*} p<0.05$ versus vehicle.

reperfusion, Western blot was performed on the right hemisphere of the brain, representative images in Figure $6 \mathrm{~A}$. In the $24 \mathrm{~h} \mathrm{MCAO} \mathrm{+} \mathrm{vehicle} \mathrm{group,} \mathrm{proteins} \mathrm{wnt3a,} \mathrm{Frz1,} \mathrm{PIWI1a,} \mathrm{and}$ FOXM1 were significantly decreased compared with the sham group ( $p<0.05$; Fig. $6 B-D, G)$, whereas p-GSK3 $\beta$ and CC- 3 were significantly increased compared with the sham group $(p<0.05$; Fig. $6 E, H)$. Additionally, at $24 \mathrm{~h}, \mathrm{HD}$ wnt $3 \mathrm{a}(1.2 \mu \mathrm{g} / \mathrm{kg})$ iN treatment after MCAO significantly upregulated the expression of Frz1, $\beta$-catenin, PIWI1a, and FOXM1 compared with vehicle groups ( $p<0.05$; Fig. $6 B-D, F, G$ ), whereas p-GSK3 $\beta$ and CC-3 were significantly attenuated compared with the vehicle group $(p<0.05$; Fig. $6 E, H)$. The $72 \mathrm{~h} \mathrm{MCAO} \mathrm{+} \mathrm{vehicle} \mathrm{group} \mathrm{wnt3a,}$ Frz1, and FOXM1 were significantly decreased compared with sham ( $p<0.05$; Fig. $6 B, C, G)$, whereas p-GSK $3 \beta$, $\beta$-catenin, and CC-3 were significantly increased compared with the sham group $(p<0.05$; Fig. $6 E, F, H)$. In the $72 \mathrm{~h} \mathrm{MCAO}+\mathrm{iN}$ wnt3a $(1.2$ $\mu \mathrm{g} / \mathrm{kg}$ ) group, wnt3a, Frz1, $\beta$-catenin, and FOXM1 levels were significantly increased compared with vehicle groups $(p<0.05$; Fig. $6 B, C, F, G)$; there was no change in PIWI1a levels at $72 \mathrm{~h}$. wnt $3 \mathrm{a}$ expression was higher in vehicle groups at 24 and $72 \mathrm{~h}$ compared with endogenous expression levels after MCAO in Figure $2 B$, which could be explained by two key observations. First, with a sample size of 4 in Figure $2 B$, the protein expression levels pro- 
A

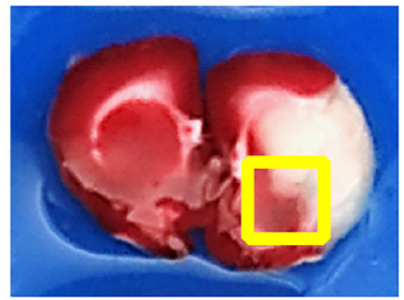

B
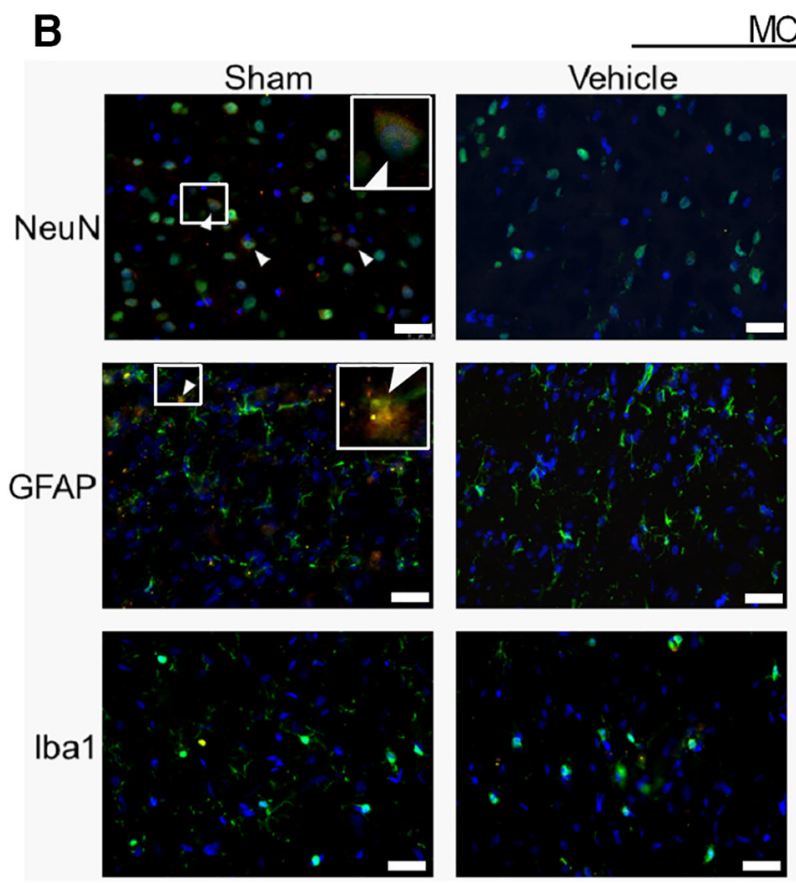

MCAO
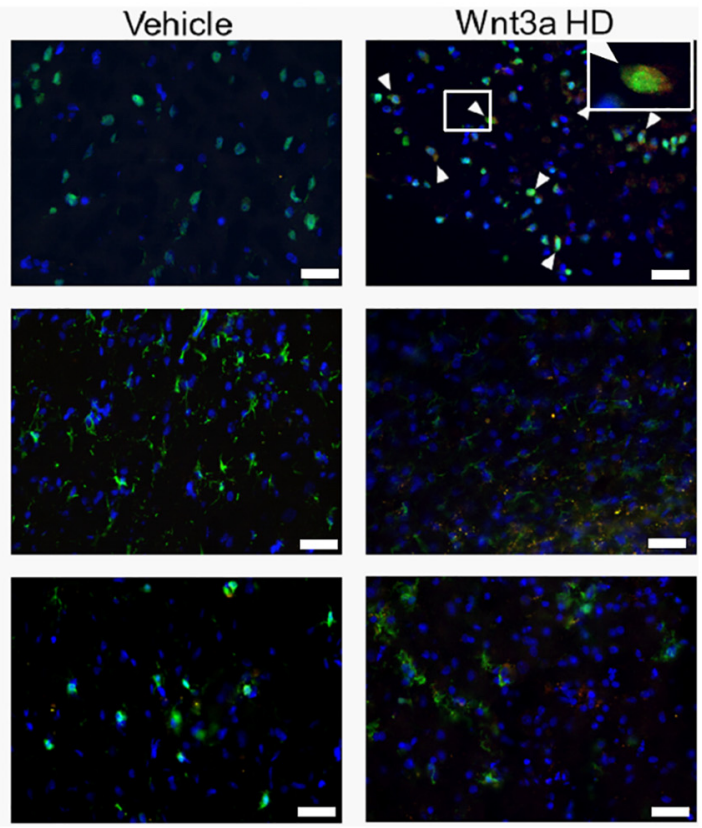

Figure 5. Expression of Frz1 (red) in neurons (NeuN, green), astrocytes (GFAP, green), and microglia (lba1, green) in sham,vehicle, and treatment. $\boldsymbol{A}$, Representative triphenyl tetrazolium chloride stained coronal section showing the location of all immunohistochemistry images indicated by the boxed region. $\boldsymbol{B}$, Expression of Frz1 decreased in vehicle at $24 \mathrm{HR}$ after MCAO in neurons but was increased with treatment. Sham showed minimal expression of Frz1 in astrocytes and no expression in microglia, whereas vehicle and HD treatment ( $1.2 \mathrm{ug} / \mathrm{kg}$ ) had no Frz1 expression in astrocytes and microglia ( $n=1$ per each group). Blue represents DAPI. Scale bar, $50 \mu \mathrm{m}$.

vided statistical significance to merit further mechanistic investigation into the significance of the pathway. Nonetheless, there still remains an opportunity for rather marked variation among small sample sizes despite statistically significant comparisons. With an increased sample size of 6 , a more quantitative evaluation of the model and wnt3a expression could be observed. Second, the vehicle solution may have slightly increased the expression of endogenous wnt3a, but this expression was still significantly lower compared with sham. Additionally, iN wnt $3 \mathrm{a}(1.2 \mu \mathrm{g} / \mathrm{kg})$ significantly decreased levels of p-GSK3 $\beta$ and CC-3 compared with the vehicle group $(p<0.05$; Fig. $6 E, H)$. Figure 6-1 (available at https://doi.org/ 10.1523/JNEUROSCI.2352-17.2018.f6-1) reports the specific statistics for each group comparison.

\section{Effects of wnt3a on infarct size and neurobehavioral function} $72 \mathrm{~h}$ after MCAO

To evaluate the effects of iN wnt3a HD $(1.2 \mu \mathrm{g} / \mathrm{kg})$ on long-term neurological outcome, infarct and neurobehavior were assessed at $72 \mathrm{~h}$. With administration of wnt3a, infarction volume was significantly reduced compared with vehicle (one-way ANOVA; Tukey's test; $F_{(2,15)}=25.20 ; n=6 ; p=0.0084$ ) (Fig. 7A). wnt3a restored modified Garcia (Fig. $7 B$ ), left forelimb placement (Fig.
7C), and corner-turn (Fig. 7D) scores to sham levels. In the $72 \mathrm{~h} \mathrm{MCAO} \mathrm{+} \mathrm{vehicle}$ group, infarction volume was significantly increased and neurobehavior scores for modified Garcia (one-way ANOVA; KruskalWallis with Dunn's post hoc; $p=0.023$; Fig. $7 B$ ), left forelimb placement (oneway ANOVA; Tukey's test; $F_{(2,15)}=8.59$; $n=6 ; p=0.003$; Fig. $7 C$ ), and cornerturn (one-way ANOVA; Tukey's test; $F_{(2,15)}=5.86 ; n=6 ; p=0.0102$; Fig. $\left.7 D\right)$ were significantly decreased compared with sham.

Impact of Frz1-siRNA, PIWI1a-siRNA, and PIWI CRISPR on the function of the wnt3a/Frz1/PIWI/FOXM1 pathway at $24 \mathrm{~h}$ after MCAO

To elucidate the molecular mechanisms modulated by wnt3a downstream of its receptor Frz1, two inhibitor groups were used: Frz1-siRNA and PIWI siRNA. At 24 h, MCAO + wnt3a + Frz1-siRNA significantly decreased the protein expression of wnt3a, Frz1, PIWI1a, and FOXM1 compared with the wnt3a-treated group $(p<0.05$; Fig. $8 B-D, F)$; pGSK $3 \beta$ and CC-3 were significantly increased compared with the wnt3a-treated and scrambled control groups ( $p<0.05$; Fig. $8 E, G)$. In the $\mathrm{MCAO}+$ wnt3a + PIWI siRNA group, Frz1, PIWI1a, and FOXM1 were significantly decreased compared with the treated and scramble control groups $(p<$ 0.05; Fig. $8 C, D, F)$; wnt $3 a$, pGSK $3 \beta$, and CC-3 were significantly increased compared with the treated and scramble control groups $(p<0.05$; Fig. $8 B, E, G)$. In the $\mathrm{MCAO}+\mathrm{wnt} 3 \mathrm{a}+$ Frz1-siRNA + PIWI CRISPR group, protein expression of PIWI1a and FOXM1 was significantly increased compared with the vehicle group $(p<0.05$; Fig. $8 D, F)$; wnt3a, Frz1, pGSK3 $\beta$, and CC-3 were significantly decreased compared with wnt3a-treated group $(p<0.05$; Fig. $8 B, C, E, G)$. Figure $8-1$ (available at https://doi.org/10.1523/JNEUROSCI.2352-17.2018. f8-1) reports the specific statistics for each group comparison.

\section{Sexually dimorphic comparisons of infarct size and} neurobehavioral function $24 \mathrm{~h}$ after MCAO in female rats

To evaluate for sexually dimorphic differences after treatment, infarct and neurobehavior were assessed at $24 \mathrm{~h}$ in female rats. With administration of wnt3a, infarction volume was significantly reduced compared with vehicle (one-way ANOVA; Tukey's test; $\left.F_{(2,15)}=53.11 ; n=6, p=0.0079\right)($ Fig. 9B). wnt3a restored modified Garcia (Fig. 9C) and left forelimb placement (Fig. 9D) scores to sham levels. HD wnt3a $(1.2 \mu \mathrm{g} / \mathrm{kg})$ treatment after MCAO had significantly therapeutic effects in both sexes, with no major intersex differences in infarct and behavioral evaluations.

Age-related effects on infarct size and neurobehavioral function $24 \mathrm{~h}$ after MCAO

To assess the age-related effects after MCAO, neurological outcome, infarct, and neurobehavior were assessed at $24 \mathrm{~h}$ in 9-month-old 


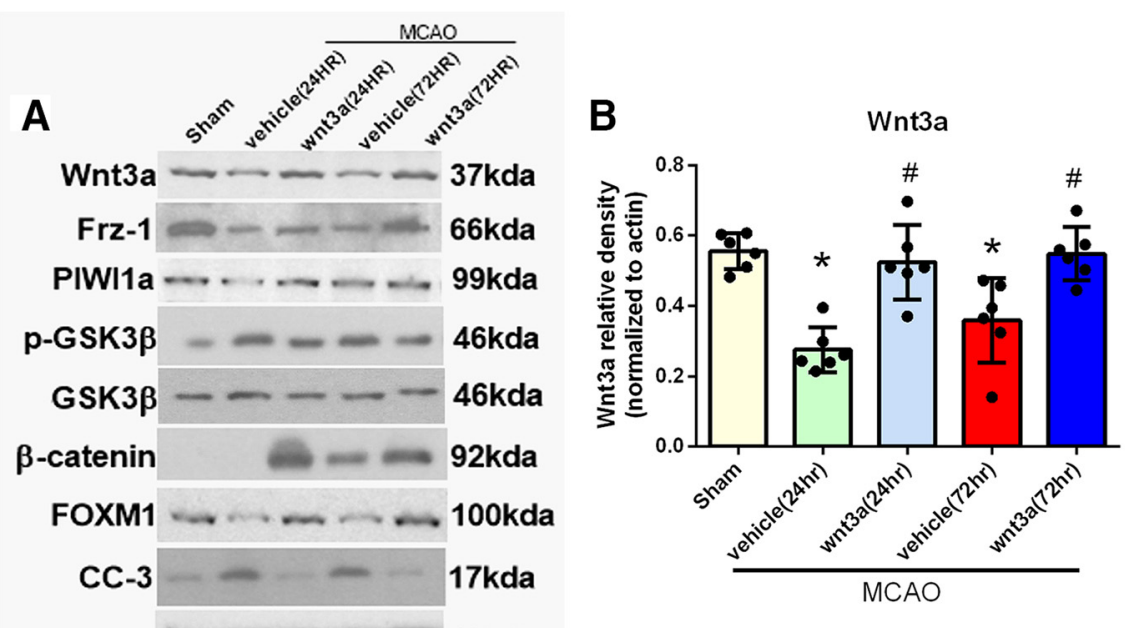

$\beta$-actin 42kda

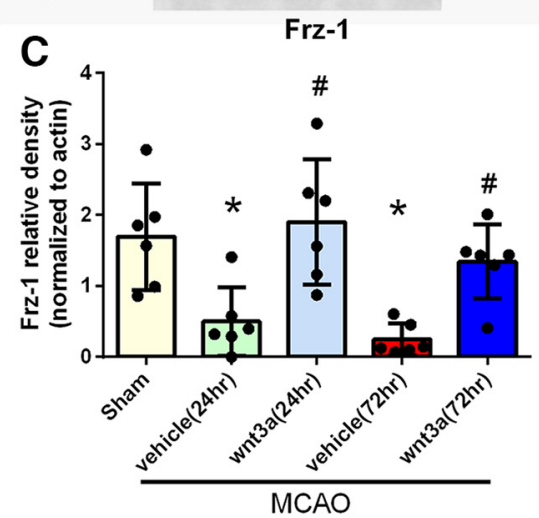

$E$
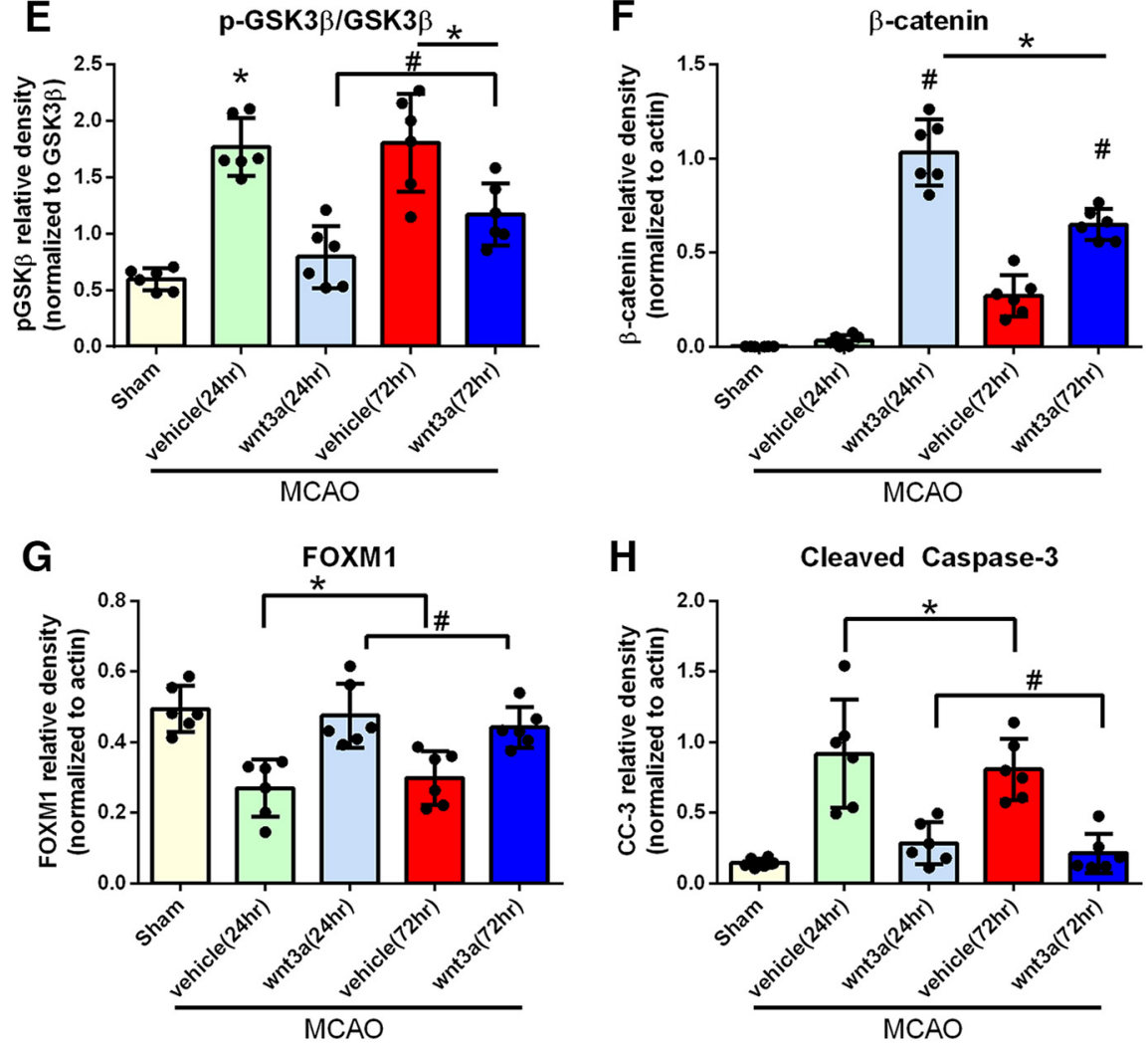

male rats. With administration of wnt $3 a$, infarction volume was significantly reduced compared with vehicle (one-way ANOVA; Tukey's test; $F_{(2,15)}=115.8 ; n=$ $6 ; p=0.0124$ ) (Fig. 10B). wnt3a had no effect on modified Garcia (Fig. 10C), and both vehicle (one-way ANOVA; KruskalWallis with Dunn's post hoc; $n=6 ; p=$ 0.0053) and treatment (one-way ANOVA; Kruskal-Wallis with Dunn's post hoc; $n=$ $6 ; p=0.0181$ ) modified Garcia scores were decreased compared with sham. wnt3a restored left forelimb placement (Fig. 10D) scores to sham levels. Overall, HD wnt3a $(1.2 \mu \mathrm{g} / \mathrm{kg})$ treatment in aged rats was not as advantageous compared with younger-treated MCAO cohorts; however, significant reduction of infarction and improved left forelimb placement was observed.

wnt $3 a$ effects on infarct size and neurobehavioral function at $24 \mathrm{~h}$ in a pMCAO model

To evaluate the model variation effects on neurological outcome, infarct and neurobehavior were assessed at $24 \mathrm{~h}$ in a pMCAO model. With administration of wnt3a, no significant improvement was seen in infarction compared with vehicle (one-way ANOVA; Tukey's test; $F_{(2,15)}=59.35 ; n=6, p=0.8816$; Fig. $11 B)$. Both modified Garcia (Fig. 11C) and left forelimb (Fig. 11D) placement showed no significant difference in treatment compared with vehicle (one-way ANOVA; Kruskal-Wallis with Dunn's post hoc; $n=6$ ).

Impact of Frz1-siRNA, PIWI1a-siRNA, and PIWI CRISPR in naive animals

Naive animals were used to evaluate the effectiveness of siRNAs and CRISPR. Naive + Frz siRNA significantly reduced Frz-1 protein levels compared with both Naive and Naive + Scrambled siRNA (one-way ANOVA; Tukey's test; $F_{(2,15)}=$ 34.15; $n=6, p<0.05$; Fig. 12A). In the Naive + PIWI1a siRNA group, PIWI1a levels were significantly attenuated compared with Naive and Naive + Scrambled siRNA (one-way ANOVA; Tukey's test;

Figure 6. wnt3a prevented apoptosis through Frz1/PIWI1a/ $\beta$-catenin/FOXM1 pathway after MCAO in rats. $\boldsymbol{A}$, Right hemisphere representative Western blots of the rat brain. wnt3a $(\boldsymbol{B})$ and $\operatorname{Frz1}(\boldsymbol{C})$ were increased after HD treatment $(1.2 \mu \mathrm{g} / \mathrm{kg})$ in both 24 and $72 \mathrm{~h}$ endpoints. D, PIWI1a was increased by wnt3a at $24 \mathrm{HR}$ but not lost its significance at $72 \mathrm{~h}$. E, pGsk-3 $\beta$ was increased in

$\leftarrow$

vehicle groups but reduced by the wnt3a treatment. $\boldsymbol{F}, \beta$-Catenin was increased by wnt3a at both time points. $G$, FOXM1 was brought back to sham levels by HD wnt3a treatment, and $(\boldsymbol{H}) \mathrm{CC}-3$ was therefore reversed in the treatment groups. Each column represents the mean \pm SD $(n=$ $6 /$ group). ${ }^{*} p<0.05$ versus Sham. ${ }^{\#} p<0.05$ versus vehicle. Figure 6-1 (available at https://doi.org/10.1523/JNEUROSCl. 2352-17.2018.f6-1) reports the specific statistics for each group comparison. 
A
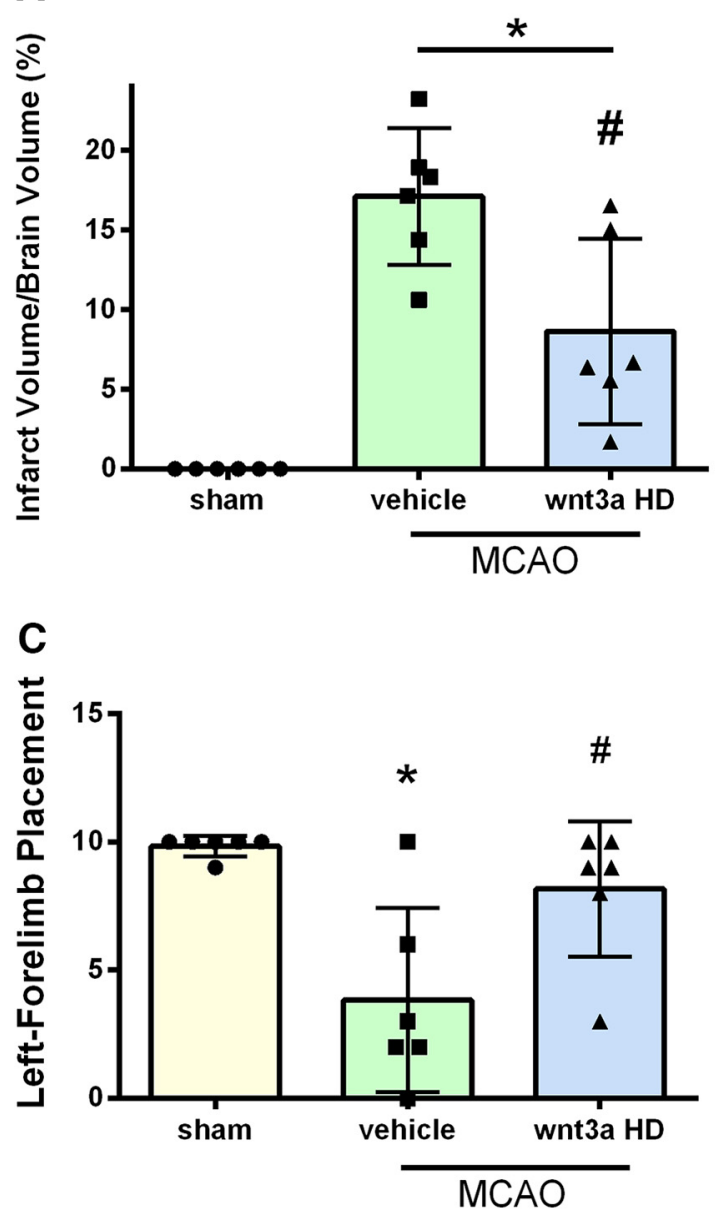

B

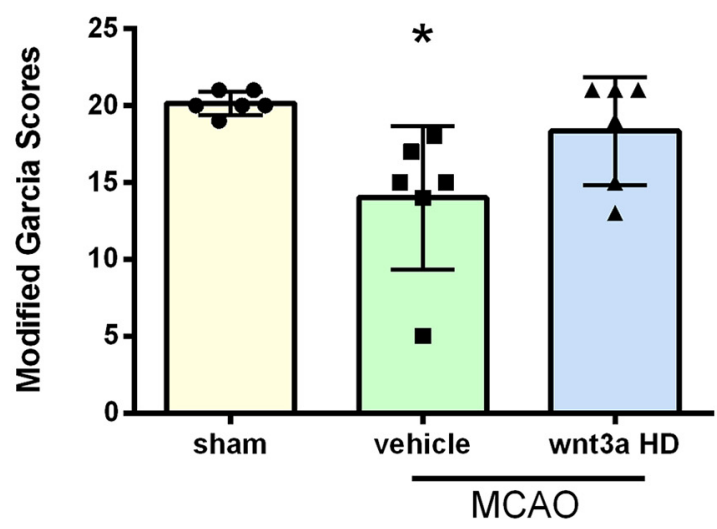

D

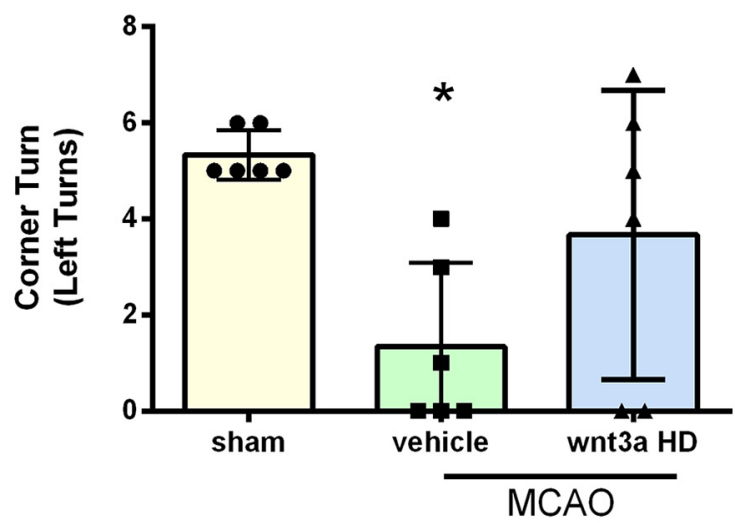

Figure 7. Wnt3a decreased infarct volume and improved neurological function 72 hours after MCA0. A, Cerebral infarct quantification was carried out on the TTC-stained images of coronal sections, (B) modified Garcia neuroscore, (C) left forelimb placement, (D) corner turn test showed that high dosage of wnt3a decreases infarction and neurological deficits 72 hours after MCA0. Each column represents the mean $\pm S D$ ( $n=6 /$ group). ${ }^{*} p<0.05$ vs. Sham, \#p $<0.05$ vs vehicle.

$F_{(3,20)}=24.51 ; n=6, p<0.05 ;$ Fig. 12B). This effect was reversed and restored to sham levels in the Naive + PIWIla CRISPR + FrzlsiRNA group (one-way ANOVA; Tukey's test; $F_{(3,20)}=34.15$; $n=6, p<0.05$; Fig. 12B).

\section{Evaluation of exogenous recombinant wnt3a in treated animals}

Because the recombinant mouse wnt3a (ab81484) protein was used for all molecular and behavioral studies, due to its homology to rat wnt $3 \mathrm{a}$, and could not be distinguished from the endogenously expressed wnt3a, a human recombinant wnt3a (ab 153563) protein with a specific tag was iN administered, $1.2 \mu \mathrm{g} / \mathrm{kg}, 1 \mathrm{~h}$ after recanalization to check delivery and presence of our drug. The human recombinant wnt3a protein was made by the parasite Schistosoma japonicum and had GST3 bound to the N-terminus to distinguish it from endogenous proteins expressed by the rat. A specific GST antibody without binding affinity for the rat glutathione S-transferase P protein (GSTP1 also known as GST3) was used to assess the amount of recombinant protein (ab153563) in our treated animals. Representative Western blots and quantitative analysis showed that the amount of recombinant wnt3a GST-specific protein was significantly higher compared with nontreated groups, both sham and vehicle (one-way ANOVA; Tukey's test; $F_{(2,15)}=285.4 ; n=6, p<0.05$; Fig. 13). Although exogenous delivery was confirmed in our study, further research is needed to thoroughly evaluate the pharmacokinetics of exogenous wnt3a administered after MCAO. Better pharmacokinetic understanding will be essential in the development of clinical applications and strengthening of wnt3a's translational impact.

\section{wnt3a and alternative coreceptor LRP6 binding}

When wnt proteins bind to Frz cell surface receptors, the transmembrane LRP5/LRP6 are recruited; and in the canonical wnt pathway, cytoplasmic protein Dishevelled (Dvl) is activated, which leads to the inhibition of GSK3 and prevention of the phosphorylation, degradation of $\beta$-catenin (Bhanot et al., 1996; Abe et al., 2013). Therefore, we further investigated the regulation of LRP6 after wnt3a treatment in MCAO. iN wnt3a (1.2 $\mu \mathrm{g} / \mathrm{kg}$ ) was administered at $1 \mathrm{~h}$ after reperfusion in treatment groups, and Western blot was performed on the right hemisphere of the brain, representative images in Figure 14. LRP6 levels were not significantly different between: sham, vehicle, MCAO + wnt3a, $\mathrm{MCAO}+$ wnt3a + scrambled-siRNA, and MCAO + wnt3a + Frz1-siRNA groups. However, the phosphorylated LRP6 levels were significantly higher in the HD $(1.2 \mu \mathrm{g} / \mathrm{kg})$ wnt3a groups compared with vehicle (one-way ANOVA; Tukey's test; $F_{(4,25)}=$ $17.76 ; n=6, p<0.05$; Fig. 14). This effect was reversed, significantly attenuating the pLRP6 expression in the MCAO + wnt3a + FrzlsiRNA group compared with $\mathrm{MCAO}+$ wnt3a (one-way ANOVA; Tukey's test; $F_{(4,25)}=17.76 ; n=6, p<0.05$; Fig. 14). 

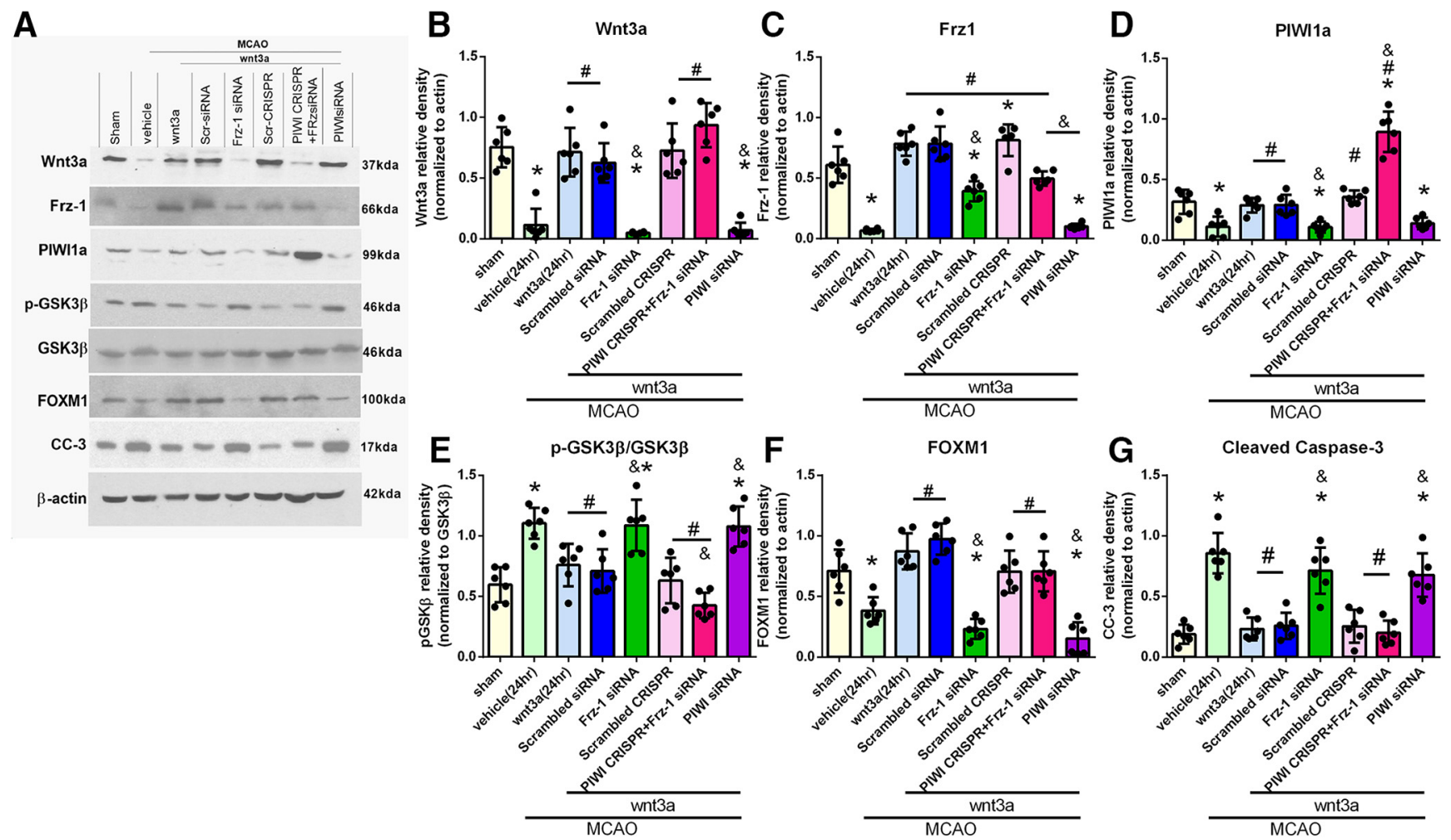

Figure 8. Effect of wnt3a preventing apoptosis through the Fr1/PIWI1a/F0XM1 pathwayat24h after MCA0.A, Righthemisphere representative Western blots of the rat brain for the pathway. $B$, After siRNA treatment of Frz1, wnt3areturned tovehiclelevels, and (C) Frz1 expression was dependent on thepresence of wnt3a, which wassignificantly reduced with Frz1-siRNAandPIWI-siRNA. With theincreased expression of PIWI1a (D) through treatment or CRISPR, pGsk-3 $\beta(\boldsymbol{E})$ was decreased. $\boldsymbol{F}$, FOXM1 was increased in expression through treatment and decreased through Frz1-siRNA and PIWI-siRNA. G, CC-3 was decreased after treatment but restored to vehicle levels bytheinhibition of theFrz1/PIWI1a/FOXM1 pathway withbothFrz1-siRNA and PIWI-siRNA. Each column representsthemean $\pm S D$ ( $n=6 /$ group). ${ }^{*} p<0.05$ versusSham. ${ }^{*} p<0.05$ versusvehicle. ${ }^{\circledR} p<0.05$ versus wnt3a. Figure 8-1 (available athttps://doi.org/10.1523/JNEUROSCI.2352-17.2018.f8-1) reports the specific statistics for each group comparison.

This suggests that the phosphorylation of LRP6 is dependent on wnt3a-Frz1 binding, which is supported in the literature: wnt3a has a $2-3 \times$ stronger affinity toward Frz1 compared with LRP6 (Bourhis et al., 2010). Phosphorylation of LRP6 may be responsible for additional regulation of GSK3 in our proposed neuronal pathway.

\section{Discussion}

In the present study, we made the following observations: (1) endogenous wnt3a and its downstream targets, Frz1/PIWI1a/FOXM1, were significantly decreased, whereas pGSK3 $\beta$ and CC-3 were significantly increased in the brain at $24 \mathrm{~h}$ after MCAO; (2) iN wnt3a decreased infarct volume and improved neurobehavioral function at $24 \mathrm{~h}$ after MCAO; (3) immunofluorescence confirmed that neurons express the receptor of wnt3a, Frz1; (4) exogenous iN wnt3a administered $1 \mathrm{~h}$ after MCAO significantly upregulated the expression of Frzl, $\beta$-catenin, PIWIla, and FOXM1 compared with vehicle groups and decreased CC-3 levels; (5) $72 \mathrm{~h}$ after MCAO, infarct size and neurobehavioral function improved after a single dose of wnt3a; (6) specific siRNAs showed links between Frz1, PIWI1a, and FOXM1 at $24 \mathrm{~h}$ after
A

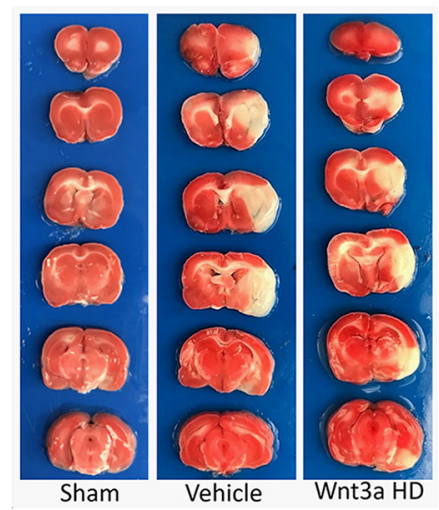

C

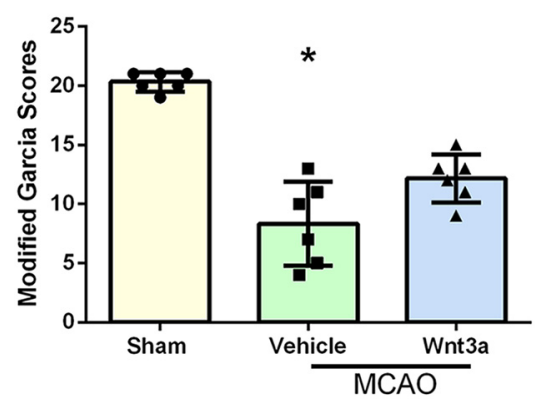

B

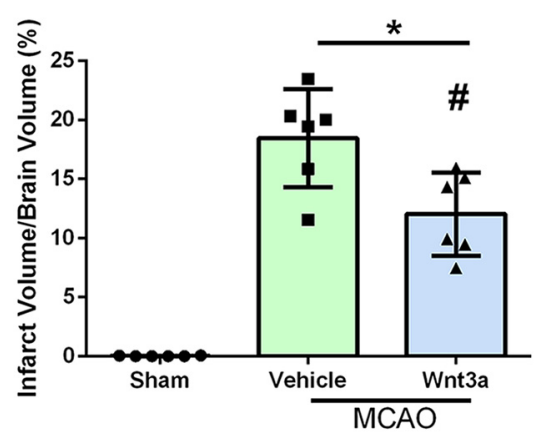

D

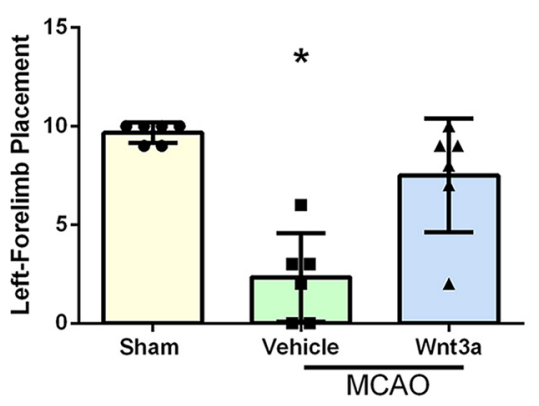

Figure 9. wnt3a attenuated infarct volume and improved neurological function $24 \mathrm{~h}$ after MCA0 in female rats. $\boldsymbol{A}$, Representative TTC staining images of coronal sections in female rats. $\boldsymbol{B}$, wnt3a HD effectively reduced the infarct volume. $\boldsymbol{C}$, Modified Garcia showed that wnt3a improved neurological function. $\boldsymbol{D}$, Left forelimb placement was improved with wnt3a. Each column represents the mean $\pm S D$ ( $n=6 /$ group). ${ }^{*} p<0.05$ versus Sham. ${ }^{\#} p<0.05$ versus vehicle. 
A

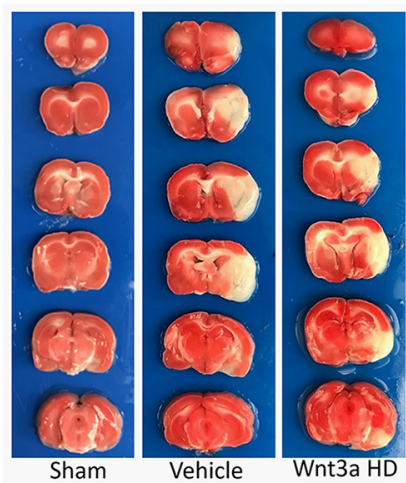

C

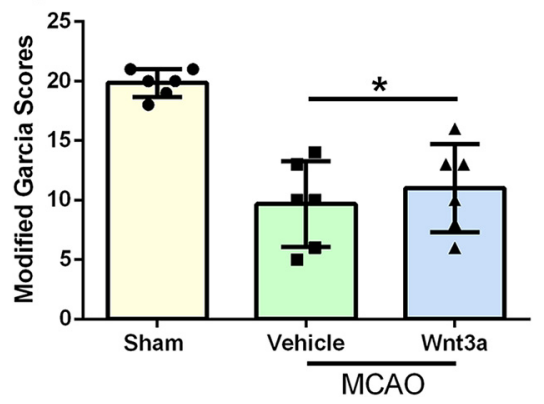

B

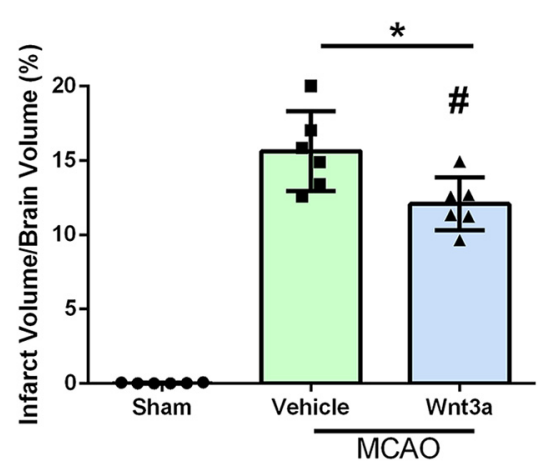

D

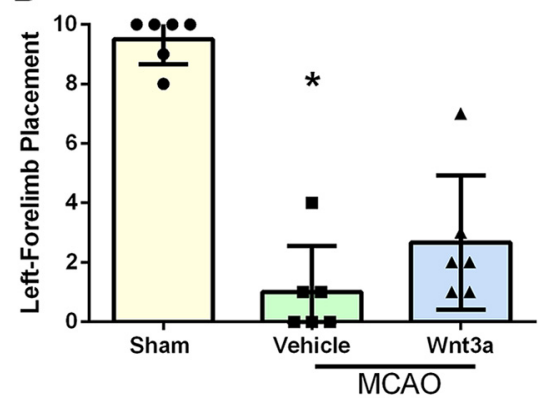

Figure 10. Nine-month-old aged rats were evaluated at $24 \mathrm{~h}$ after MCAO and showed a reduction in infarct volume with an improved left forelimb placement after wnt3a administration. $\boldsymbol{A}$, Representative TTC staining images of coronal sections in aged rats. $\boldsymbol{B}$, wnt3a effectively reduced infarct volume compared with vehicle. $\boldsymbol{C}$, Modified Garcia was not able to detect an effect after wnt3a administration compared with vehicle. $\boldsymbol{D}$, Left forelimb placement was improved with wnt3a. Each column represents the mean $\pm S D$ ( $n=6 /$ group). ${ }^{*} p<0.05$ versus Sham. ${ }^{*} p<0.05$ versus vehicle.

A

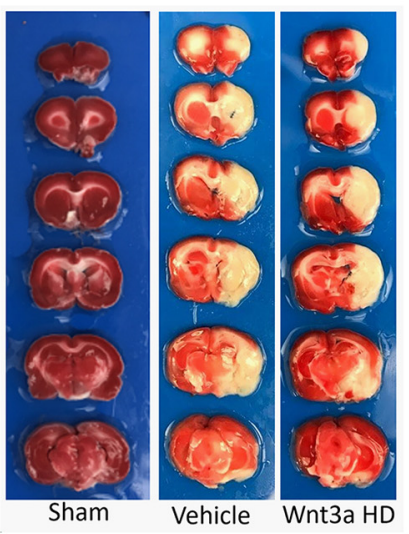

C

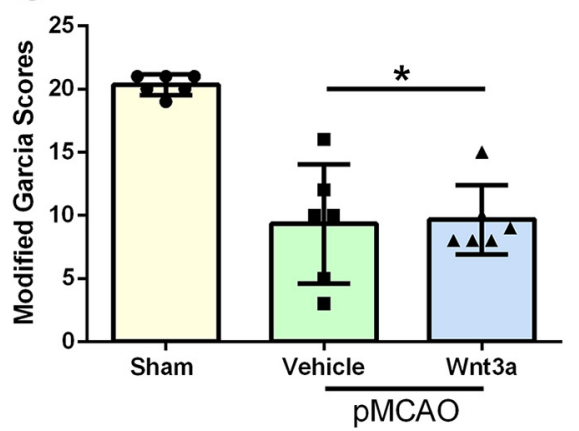

B

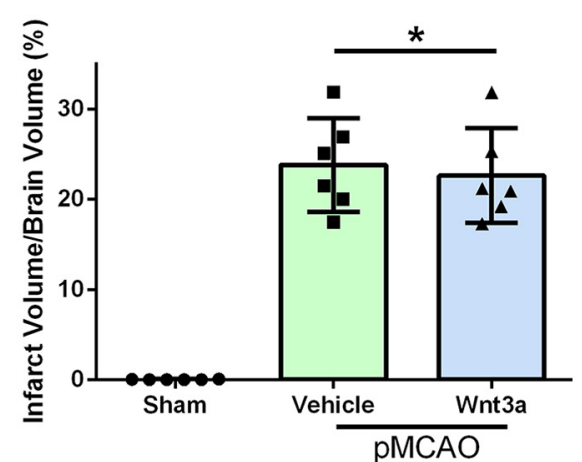

D

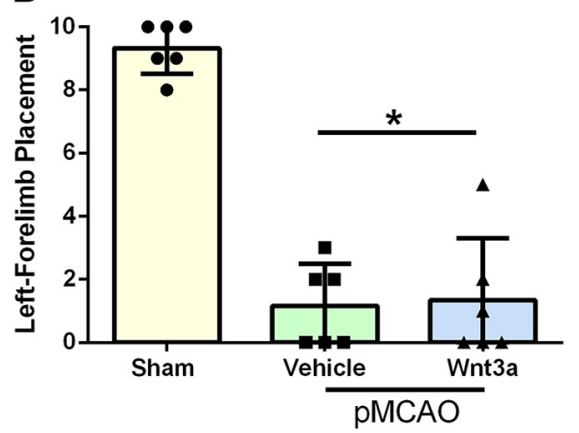

Figure 11. Infarct volumes $24 \mathrm{~h}$ after pMCAO. $\boldsymbol{A}$, Representative TTC staining images of coronal sections. $\boldsymbol{B}$, wnt $3 \mathrm{a}$ HD had no effect on infarct in the pMCAO compared with vehicle. $\boldsymbol{C}$, Modified Garcia showed no improvement in neurological function after wnt3a administration. $\boldsymbol{D}$, Left forelimb placement showed no improvement after wnt3a treatment compared with vehicle. Each column represents the mean $\pm S D$ ( $n=6 /$ group). ${ }^{*} p<0.05$ versus Sham.

MCAO; (7) the same efficacy of wnt3a after stroke was seen in female rats, but the effect was diminished in aged rats; and (8) in the pMCAO model, no significant difference was observed between vehicle and wnt3a groups.

wnt3a caused significant increase in PIWI1a and FOXM1 and a decrease in CC-3 at $24 \mathrm{~h}$ after wnt3a administration. At $72 \mathrm{~h}$, in the vehicle group, PIWI1a levels were restored to prestroke levels. This result suggests that either the modest recovery of endogenous wnt $3 a$ levels at $72 \mathrm{~h}$ or an alternate pathway is responsible for the upregulation of $\beta$-catenin, PIWIla, and FOXM1 levels $72 \mathrm{~h}$ after MCAO. In the literature, although $\beta$-catenin expression was endogenously elevated at $72 \mathrm{~h}$ after subarachnoid hemorrhage (SAH), neuronal survival was not significantly improved (Chen et al., 2015). In this study, the higher $\beta$-catenin expression after wnt3a treatment significantly reduced apoptosis at 24 and $72 \mathrm{~h}$ endpoints.

To confirm that PIWI1a regulates FOXM1, a specific inhibitor of PIWIla, PIWI1a-siRNA, was administered with wnt3a. This intervention caused a significant decrease in FOXM1 expression at $24 \mathrm{~h}$. To further investigate the possibility of an alternative pathway, two groups were added: wnt3a + Frzl-siRNA + MCAO and wnt3a + Frzl-siRNA + PIWIla-CRISPR-activation + MCAO. In the cohort of wnt3a + FrzlsiRNA + MCAO, we saw a significant reduction of PIWI1a and FOXM1; however, in wnt3a + Frzl-siRNA + PIWIla-CRISPRactivation + MCAO, PIWIla levels were significantly increased with an associated increase in FOXM1 levels and a reduction in CC-3. These mechanistic studies support a link between PIWI1a and FOXM1.

Studies have shown a significant association between PIWIL1a and regulation of $\beta$-catenin (Reeves et al., 2012), but PIWIL1a has not been mechanistically linked with wnt3a or downstream signaling after stroke. We found that PIWIla significantly decreased the levels of active p-GSK $3 \beta$ and significantly rescued levels of survival protein $\beta$-catenin. Inhibition of PIWI1 a significantly increased levels of p-GSK3 $\beta$, suggesting that PIWIla is an upstream regulator of GSK3 $\beta$. A link between Frz1 and p-GSK3 $\beta$ is supported by increased p-GSK3 $\beta$ secondary to Frz1siRNA. To confirm PIWIla's role downstream of Frz1, PIWI1a was upregulated via CRISPR in combination with siRNA Frz1 knockdown. This upregulation of PIWIla significantly downregulated p-GSK3 $\beta$.

Frz1 has been reportedly activated by wnt3a and shown to be neuroprotective 


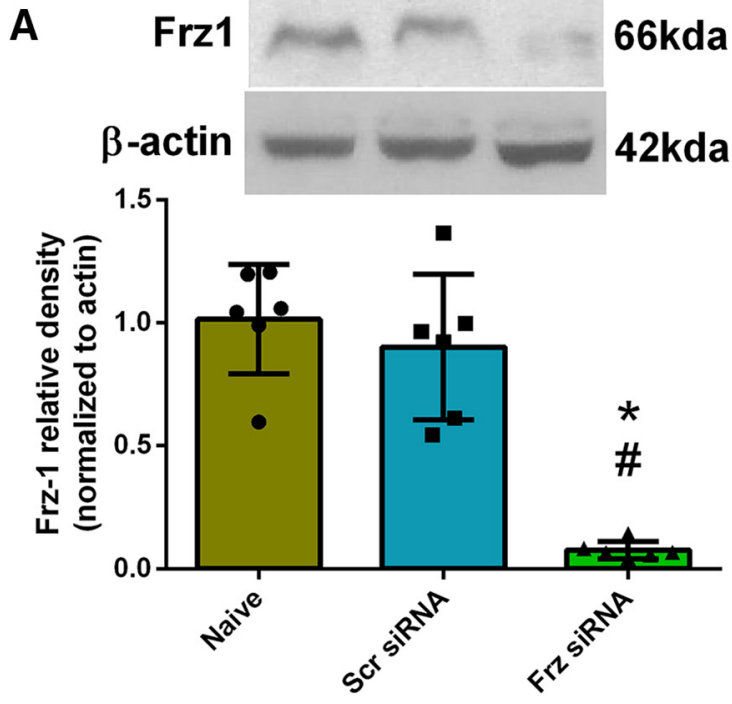

B

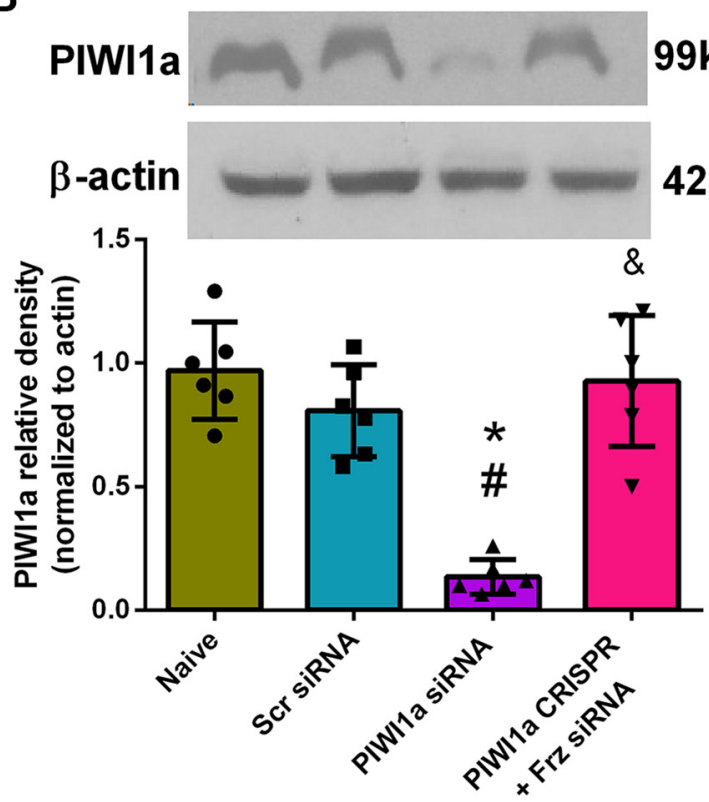

Figure 12. Naive-treated animals showed a significant reduction of Frz-1 with Frz siRNA. $\boldsymbol{A}$, Representative Western blots of the right hemisphere of the rat brain and quantitative analysis showed that the expression of Frz-1 significantly decreased at $24 \mathrm{~h}$ after Frz-siRNA administration compared with Naive and Naive + Scrambled-siRNA $(p<0.05)$. B, PIWI1a levels were significantly attenuated in the Naïve + PIWI1a siRNA group compared to Naïve and Naiive + Scrambled siRNA groups. PIWI1a levels were restored to sham levels in the Naive + PIWI1a-CRISPR + Frz1-siRNA group. Each column represents the mean \pm SD ( $n=6 /$ group). ${ }^{*} p<0.05$ versus Naive. ${ }^{\#} p<0.05$ versus Naive + Scrambled-siRNA.

against $\mathrm{A} \beta$ oligomers (Chacón et al., 2008). We confirmed the presence of Frzl in neurons using immunohistochemistry and noticed an increased expression of Frz1 in the penumbra of the wnt3 + MCAO group. Western blots supported that iN administration of wnt 3 a significantly increased the expression of Frz1 at 24 and $72 \mathrm{~h}$. These findings suggest a positive feedback loop involving wnt3a and Frz1. Additionally, the inhibition of PIWI1a with siRNA resulted in decreased expression of Frz1, indicating that Frz1 may be transcriptionally regulated downstream of PIWI1a. Congruently, the canonical wnt3a/Frzl pathway in cancer tissues significantly decreased certain miRNAs (e.g., miR-204 for Frz1), which may be a variable in the increased expression of

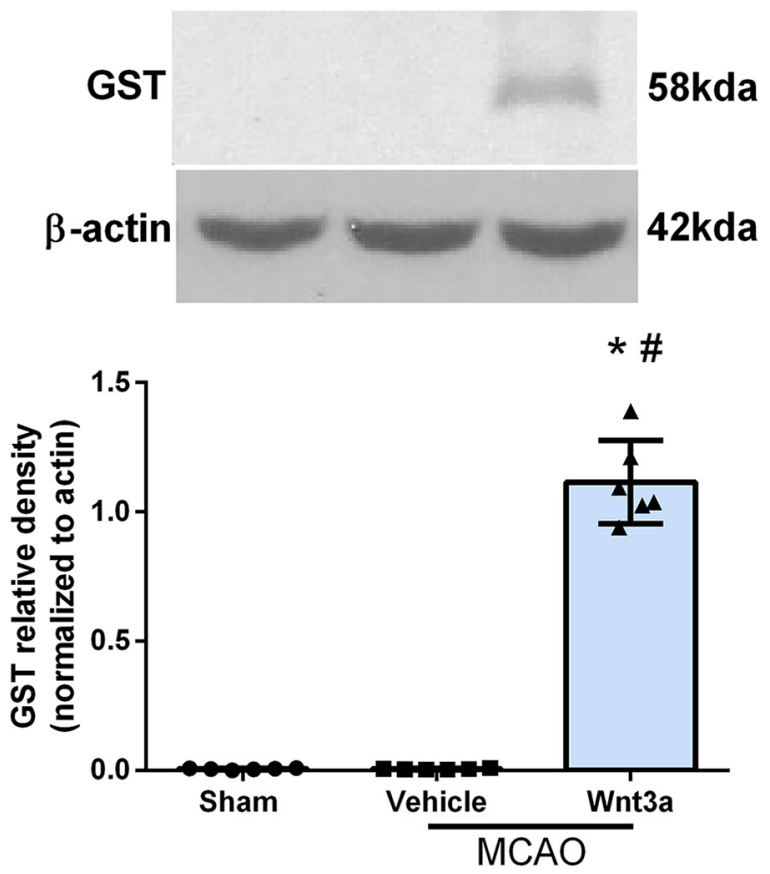

Figure 13. Western blot confirmed the delivery of wnt3a in our treated animals. Right hemisphere representative Western blots of the rat brain and quantitative analysis showed that the expression of recombinant GST-specific tagged wnt3a protein was significantly higher compared with nontreated groups, both sham and vehicle. Each column represents the mean \pm SD ( $n=6 /$ group). ${ }^{*} p<0.05$ versus Sham. ${ }^{*} p<0.05$ versus vehicle.

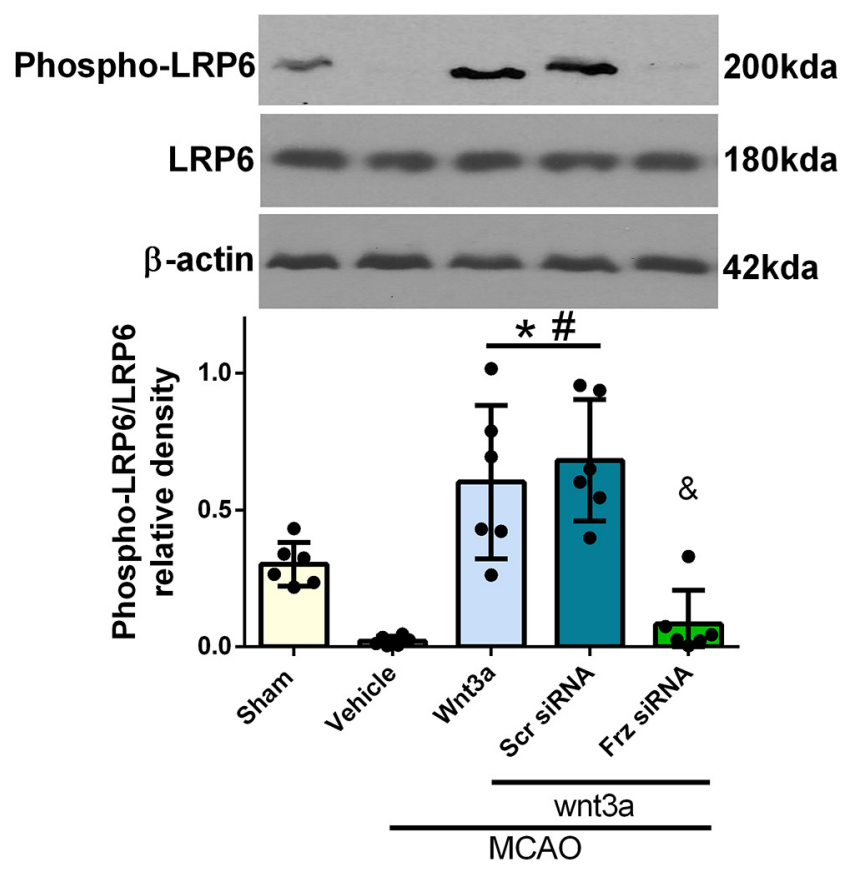

Figure 14. LRP6 expression and activation after MCAO in rats. Right hemisphere representative Western blots of the rat brain for LRP6, pLRP6, and actin. Overall LRP6 expression was not significant between groups. However, phosphorylation of LRP significantly increased in the HD treatment $(1.2 \mu \mathrm{g} / \mathrm{kg})$ treated groups, which was reversed in the Frz1-siRNA at 24HR after MCA0. Each column represents the mean \pm SD ( $n=6$ /group). ${ }^{*} p<0.05$ versus Sham. ${ }^{*} p<$ 0.05 versus vehicle. ${ }^{\circledR} p<0.05$ versus wnt $3 a+S c r$ siRNA.

the Frz1 receptor (Ueno et al., 2013). The Frz1-positive feedback loop requires further investigation. Inhibition of Frz1 downregulated wnt3a, PIWI1a, $\beta$-catenin, and FOXM1 while upregulating p-GSK $3 \beta$ and CC-3 expression at $24 \mathrm{~h}$. 
Interestingly, wnt3a protein expression was significantly reduced in the Frzl-siRNA group. In support of this finding, miR-34 was observed to directly attenuate wnt3a protein expression in breast cancer tissues (Song et al., 2015). In gastric carcinoma cells, TGF- $\beta$ induces caspase- 8 activation and apoptosis by phosphorylating R-Smads, which form complexes with their common mediator, Smad4, and enter the nucleus to regulate gene expression (Moustakas and Heldin, 2005). This Smad complex has been shown to attenuate the wnt expression in cancer cell lines (Pang et al., 2011). A potential upstream link exists via the ability of GSK $3 \beta$ to phosphorylate and activate Smad4 to lower the expression of wnt $3 a$, an effect that is reversed after wnt3a treatment in HEK cells (Demagny et al., 2014). In light of several promising hypotheses, further research is needed to elucidate the gene regulation of wnt3a after Frz1 siRNA treatment in neurons after MCAO in the rat model. Despite these limitations, we can conclude that wnt3a exerts neuroprotective effects on PIWI1a/ $\beta$ catenin/FOXM1 through the Frz1 receptor.

In the present study, we investigated two proapoptotic proteins, pGSK $3 \beta$ and CC-3. GSK- $3 \beta$ is reported to participate in neuron death through $\mathrm{PI} 3 \mathrm{~K} / \mathrm{AKT}$ and wnt $/ \beta$-catenin signaling pathways after stroke (Chen et al., 2016). Also, after MCAO, CC-3 significantly increased and caused apoptosis in neurons ( $\mathrm{Li}$ et al., 2017). Paralleling these findings, we observed an increase in pGSK $3 \beta$ and CC- 3 at 24 and $72 \mathrm{~h}$ after MCAO. These effects were directly reversed with iN wnt3a treatment. This reduction in neuronal apoptotic proteins with wnt3a administration was associated with significant neurobehavior improvement in forelimb placement and recovery of modified Garcia scores to sham levels. Studies have shown that MCAO causes deleterious neurological effects on modified Garcia (Wang et al., 2017) and left forelimb placement (Senda et al., 2011), tests that correlate with cerebral infarction. We examined the neuropathological damage at 24 and $72 \mathrm{~h}$ after MCAO and found our model to create significant neurological deficits. wnt3a caused a significant reduction of infarction volumes and neurological deficits in female rats. Efficacy of wnt3a diminished with age, but significant benefits were seen in both infarct volume and forelimb placement. In a permanent occlusion model, there was no change after wnt3a administration in infarct volume and neurological outcome. The proposed mechanism of action of wnt 3 a requires interaction of wnt 3 a with receptors, and thus direct sanguineous exposure to the area of infarction is likely required for therapeutic effect. While the penumbra of the infarction zone receives some perfusion and thus wnt3a exposure in models of permanent occlusion, without reperfusion, there is limited opportunity for rescue of severely hypoxic penumbra. In agreement with our findings, a significant number of proposed neuroprotective agents have only demonstrated effectiveness in animal models of transient occlusion (Min et al., 2013). Although wnt3a administered restored neurological testing scores to sham levels in treatment groups, significance was only seen versus vehicle groups in left forelimb placement tests. While infarction volume is known to affect neurobehavior tests, these tests are not individually optimal to evaluate the total damage in the stroke because each test is sensitive to specific focal neurological deficits (Senda et al., 2011); nonetheless, this treatment shows promise in stroke rehabilitation.

Treatments targeting the CNS that are administered outside of the CNS must be able to efficiently cross the blood-brain barrier (Thorne and Frey, 2001). iN administration of neuroprotectants has previously been established as a viable route of administration for stroke, allowing rapid delivery to the CNS and ease of administration (Lin et al., 2009). We found that wnt3a's delivery via an iN route was feasible and provided neuroprotection after stroke. Thus, iN administration of wnt3a is a clinically translatable route of administration, lowering risk of systemic side effects.

One limitation of this study is that the design and results do not fully exclude the possibility of alternative pathways that act on wnt3a and downstream mediators; thus, further research will need to investigate the relationship between PIWI1a, $\beta$-catenin, FOXM1, and the canonical apoptosis pathway to fully exclude or incorporate alternative pathways that may play a role in wnt3a physiology. For example, $\beta$-catenin canonically is known to translocate into the nucleus and act as a transcriptional coactivator of transcription factors that belong to the TCF/LEF family (Rao and Kühl, 2010). wnt3a is known to bind to Frzla, expressed by dendrites (Oderup et al., 2013) and microglia, which may play a role in the regulation of apoptosis in neurons. Additionally, GSK $3 \beta$ is part of the destruction complex (APC, Axin, and CK1) (Minde et al., 2011) of $\beta$-catenin and can be regulated by these intrinsic proteins, a process in which PIWI1 a may be a significant player. Further mechanistic studies of these three proteins independently need to be investigated to fully understand the role of PIWI1a in the wnt3a pathway.

In conclusion, $\mathrm{iN}$ administration of wnt $3 \mathrm{a}$ was efficacious in neuroprotection against transient cerebral ischemia in rats. New pathway links between Frz1, PIWI1a, and FOXM1 have been established by which wnt3a works in neurons to inhibit caspase3-dependent apoptosis. A working model of these relationships is shown in Figure 1. Given the lack of treatment options for ischemic brain injury after stroke, these findings provide a basis for clinical trials to advance the clinical management of stroke and a foundation for future research in similar pathologies. wnt3a iN delivery should be investigated further as a potential therapeutic option for ischemic stroke.

\section{References}

Abe T, Zhou P, Jackman K, Capone C, Casolla B, Hochrainer K, Kahles T, Ross ME, Anrather J, Iadecola C (2013) Lipoprotein receptor-related protein-6 protects the brain from ischemic injury. Stroke 44:2284-2291. CrossRef Medline

Arrázola MS, Silva-Alvarez C, Inestrosa NC (2015) How the Wnt signaling pathway protects from neurodegeneration: the mitochondrial scenario. Front Cell Neurosci 9:166. CrossRef Medline

Ayer RE, Jafarian N, Chen W, Applegate RL 2nd, Colohan AR, Zhang JH (2012) Preoperative mucosal tolerance to brain antigens and a neuroprotective immune response following surgical brain injury. J Neurosurg 116:246-253. CrossRef Medline

Bhanot P, Brink M, Samos CH, Hsieh JC, Wang Y, Macke JP, Andrew D, Nathans J, Nusse R (1996) A new member of the frizzled family from Drosophila functions as a wingless receptor. Nature 382:225-230. CrossRef Medline

Bortesi L, Fischer R (2015) The CRISPR/Cas9 system for plant genome editing and beyond. Biotechnol Adv 33:41-52. CrossRef Medline

Bourhis E, Tam C, Franke Y, Bazan JF, Ernst J, Hwang J, Costa M, Cochran AG, Hannoush RN (2010) Reconstitution of a frizzled8.wnt3a.LRP6 signaling complex reveals multiple wnt and Dkk1 binding sites on LRP6. J Biol Chem 285:9172-9179. CrossRef Medline

Candelario-Jalil E (2009) Injury and repair mechanisms in ischemic stroke: considerations for the development of novel neurotherapeutics. Curr Opin Investig Drugs 10:644-654. Medline

Cerpa W, Toledo EM, Varela-Nallar L, Inestrosa NC (2009) The role of wnt signaling in neuroprotection. Drug News Perspect 22:579-591. CrossRef Medline

Chacón MA, Varela-Nallar L, Inestrosa NC (2008) Frizzled-1 is involved in the neuroprotective effect of wnt3a against abeta oligomers. J Cell Physiol 217:215-227. CrossRef Medline 
Chen C, Ostrowski RP, Zhou C, Tang J, Zhang JH (2010) Suppression of hypoxia-inducible factor-1alpha and its downstream genes reduces acute hyperglycemia-enhanced hemorrhagic transformation in a rat model of cerebral ischemia. J Neurosci Res 88:2046-2055. CrossRef Medline

Chen S, Ma Q, Krafft PR, Hu Q, Rolland W 2nd, Sherchan P, Zhang J, Tang J, Zhang JH (2013) P2X7R/cryopyrin inflammasome axis inhibition reduces neuroinflammation after SAH. Neurobiol Dis 58:296-307. CrossRef Medline

Chen W, Ma Q, Suzuki H, Hartman R, Tang J, Zhang JH (2011) Osteopontin reduced hypoxia-ischemia neonatal brain injury by suppression of apoptosis in a rat pup model. Stroke 42:764-769. CrossRef Medline

Chen Y, Zhang Y, Tang J, Liu F, Hu Q, Luo C, Tang J, Feng H, Zhang JH (2015) Norrin protected blood-brain barrier via frizzled-4/ $\beta$-catenin pathway after subarachnoid hemorrhage in rats. Stroke 46:529-536. CrossRef Medline

Chen X, Liu Y, Zhu J, Lei S, Dong Y, Li L, Jiang B, Tan L, Wu J, Yu S, Zhao Y (2016) GSK-3 $\beta$ downregulates Nrf2 in cultured cortical neurons and in a rat model of cerebral ischemia-reperfusion. Sci Rep 6:20196. CrossRef Medline

Cohen P, Goedert M (2004) GSK3 inhibitors: development and therapeutic potential. Nat Rev Drug Discov 3:479-487. CrossRef Medline

Collino M, Aragno M, Castiglia S, Tomasinelli C, Thiemermann C, Boccuzzi G, Fantozzi R (2009) Insulin reduces cerebral ischemia/reperfusion injury in the hippocampus of diabetic rats. Diabetes 58:235-242. CrossRef Medline

Demagny H, Araki T, De Robertis EM (2014) The tumor suppressor Smad4/DPC4 is regulated by phosphorylations that integrate FGF, wnt, and TGF- $\beta$ signaling. Cell Rep 9:688-700. CrossRef Medline

Ferrer I, Planas AM (2003) Signaling of cell death and cell survival following focal cerebral ischemia: life and death struggle in the penumbra. J Neuropathol Exp Neurol 62:329-339. CrossRef Medline

Fisher M, Brott TG (2003) Emerging therapies for acute ischemic stroke new therapies on trial. Stroke 34:359-361. CrossRef Medline

Gratz SJ, Cummings AM, Nguyen JN, Hamm DC, Donohue LK, Harrison MM, Wildonger J, O'Connor-Giles KM (2013) Genome engineering of Drosophila with the CRISPR RNA-guided Cas9 nuclease. Genetics 194: 1029-1035. CrossRef Medline

Horvath P, Barrangou R (2010) CRISPR/Cas, the immune system of bacteria and archaea. Science 327:167-170. CrossRef Medline

Hu Q, Chen C, Yan J, Yang X, Shi X, Zhao J, Lei J, Yang L, Wang K, Chen L, Huang H, Han J, Zhang JH, Zhou C (2009) Therapeutic application of gene silencing MMP-9 in a middle cerebral artery occlusion-induced focal ischemia rat model. Exp Neurol 216:35-46. CrossRef Medline

Inestrosa NC, Varela-Nallar L (2014) Wnt signaling in the nervous system and in Alzheimer's disease. J Mol Cell Biol 6:64-74. CrossRef Medline

Jiang L, Wang P, Chen L, Chen H (2014) Downregulation of FoxM1 by thiostrepton or small interfering RNA inhibits proliferation, transformation ability and angiogenesis, and induces apoptosis of nasopharyngeal carcinoma cells. Int J Clin Exp Pathol 7:5450-5460. Medline

Jiang W, Bikard D, Cox D, Zhang F, Marraffini LA (2013) RNA-guided editing of bacterial genomes using CRISPR-cas systems. Nat Biotechnol 31:233-239. CrossRef Medline

Jinek M, Chylinski K, Fonfara I, Hauer M, Doudna JA, Charpentier E (2012) A programmable dual-RNA-guided DNA endonuclease in adaptive bacterial immunity. Science 337:816-821. CrossRef Medline

Kawabori M, Kacimi R, Kauppinen T, Calosing C, Kim JY, Hsieh CL, Nakamura MC, Yenari MA (2015) Triggering receptor expressed on myeloid cells 2 (TREM2) deficiency attenuates phagocytic activities of microglia and exacerbates ischemic damage in experimental stroke. J Neurosci 35: 3384-3396. CrossRef Medline

Kelly S, Zhao H, Hua Sun G, Cheng D, Qiao Y, Luo J, Martin K, Steinberg GK, Harrison SD, Yenari MA (2004) Glycogen synthase kinase $3 \beta$ inhibitor Chir025 reduces neuronal death resulting from oxygen-glucose deprivation, glutamate excitotoxicity, and cerebral ischemia. Exp Neurol 188: 378-386. CrossRef Medline

Kusaka I, Kusaka G, Zhou C, Ishikawa M, Nanda A, Granger DN, Zhang JH, Tang J (2004) Role of AT1 receptors and NAD(P)H oxidase in diabetesaggravated ischemic brain injury. Am J Physiol Heart Circ Physiol 286: H2442-H2451. CrossRef Medline

Lai TW, Zhang S, Wang YT (2014) Excitotoxicity and stroke: identifying novel targets for neuroprotection. Prog Neurobiol 115:157-188. CrossRef Medline
Lin S, Fan LW, Rhodes PG, Cai Z (2009) Intranasal administration of IGF-1 attenuates hypoxic-ischemic brain injury in neonatal rats. Exp Neurol 217:361-370. CrossRef Medline

Liu L, Puri KD, Penninger JM, Kubes P (2007) Leukocyte PI3Kgamma and $\mathrm{PI} 3 \mathrm{~K} \delta$ have temporally distinct roles for leukocyte recruitment in vivo. Blood 110:1191-1198. CrossRef Medline

Li C, Che LH, Ji TF, Shi L, Yu JL (2017) Effects of the TLR4 signaling pathway on apoptosis of neuronal cells in diabetes mellitus complicated with cerebral infarction in a rat model. Sci Rep 7:srep43834. CrossRef Medline

MacDonald BT, Tamai K, He X (2009) Wnt/ $\beta$-catenin signaling: components, mechanisms, and diseases. Dev Cell 17:9-26. CrossRef Medline

Mackay J, Mensah G (2004) Atlas of heart disease and stroke, Ed 1. Geneva: World Health Organization.

Mali P, Yang L, Esvelt KM, Aach J, Guell M, DiCarlo JE, Norville JE, Church GM (2013) RNA-guided human genome engineering via Cas9. Science 339:823-826. CrossRef Medline

McBride DW, Tang J, Zhang JH (2016) Development of an infarct volume algorithm to correct for brain swelling after ischemic stroke in rats. Acta Neurochir Suppl 121:103-109. CrossRef Medline

Michalski D, Heindl M, Kacza J, Laignel F, Kappers-Tiedt L, Schneider D, Grosche J, Boltze J, Lahr M, Hobohm C, Hartig W (2012) Spatiotemporal course of macrophage-like cell accumulation after experimental embolic stroke depending on treatment with tissue plasminogen activator and its combination with hyperbaric oxygenation. Eur J Histochem 56:14. CrossRef Medline

Min J, Farooq MU, Gorelick PB (2013) Neuroprotective agents in ischemic stroke: past failures and future opportunities. Clin Invest 3:1167-1177. CrossRef

Minde DP, Anvarian Z, Rüdiger SG, Maurice MM (2011) Messing up disorder: how do missense mutations in the tumor suppressor protein APC lead to cancer? Mol Cancer 10:101. CrossRef Medline

Moustakas A, Heldin CH (2005) Non-Smad TGF- $\beta$ signals. J Cell Sci 118: 3573-3584. CrossRef Medline

Oderup C, LaJevic M, Butcher EC (2013) Canonical and noncanonical Wnt proteins program dendritic cell responses for tolerance. J Immunol 190: 6126-6134. CrossRef Medline

Pang L, Qiu T, Cao X, Wan M (2011) Apoptotic role of TGF- $\beta$ mediated by Smad4 mitochondria translocation and cytochrome c oxidase subunit II interaction. Exp Cell Res 317:1608-1620. CrossRef Medline

Perez-Pinera P, Kocak DD, Vockley CM, Adler AF, Kabadi AM, Polstein LR, Thakore PI, Glass KA, Ousterout DG, Leong KW, Guilak F, Crawford GE, Reddy TE, Gersbach CA (2013) RNA-guided gene activation by CRISPRCas9-based transcription factors. Nat Methods 10:973-976. CrossRef Medline

R\&D Systems (2018) Wnt receptors and pathways. https://www.rndsystems. com/resources/articles/wnt-receptors-pathways.

Rao TP, Kühl M (2010) An updated overview on wnt signaling pathways: a prelude for more. Circ Res 106:1798-1806. CrossRef Medline

Reeves ME, Baldwin ML, Aragon R, Baldwin S, Chen ST, Li X, Mohan S, Amaar YG (2012) RASSF1C modulates the expression of a stem cell renewal gene, PIWIL1. BMC Res Notes 5:239. CrossRef Medline

Rha JH, Saver JL (2007) The impact of recanalization on ischemic stroke outcome: a meta-analysis. Stroke 38:967-973. CrossRef Medline

Roth JM (2011) Recombinant tissue plasminogen activator for the treatment of acute ischemic stroke. Proc Bayl Univ Med Cent 24:257-259. CrossRef Medline

Schmued LC, Stowers CC, Scallet AC, Xu L (2005) Fluoro-jade C results in ultra high resolution and contrast labeling of degenerating neurons. Brain Res 1035:24-31. CrossRef Medline

Senda DM, Franzin S, Mori MA, de Oliveira RM, Milani H (2011) Acute, post-ischemic sensorimotor deficits correlate positively with infarct size but fail to predict its occurrence and magnitude after middle cerebral artery occlusion in rats. Behav Brain Res 216:29-35. CrossRef Medline

Shruster A, Ben-Zur T, Melamed E, Offen D (2012) Wnt signaling enhances neurogenesis and improves neurological function after focal ischemic injury. PLoS One 7:e40843. CrossRef Medline

Song JL, Nigam P, Tektas SS, Selva E (2015) microRNA regulation of wnt signaling pathways in development and disease. Cell Signal 27:13801391. CrossRef Medline 
Taylor RA, Sansing LH (2013) Microglial responses after ischemic stroke and intracerebral hemorrhage. J Immunol Res 2013:e746068. CrossRef Medline

Thorne RG, Frey WH 2nd (2001) Delivery of neurotrophic factors to the central nervous system: pharmacokinetic considerations. Clin Pharmacokinet 40:907-946. CrossRef Medline

Ueno K, Hirata H, Hinoda Y, Dahiya R (2013) Frizzled homolog proteins, microRNAs and wnt signaling in cancer. Int J Cancer 132:1731-1740. CrossRef Medline

Wang Y, Sherchan P, Huang L, Akyol O, McBride DW, Zhang JH (2017) Naja sputatrix venom preconditioning attenuates neuroinflammation in a rat model of surgical brain injury via PLA2/5-LOX/LTB4 cascade activation. Sci Rep 7:5466. CrossRef Medline
Wu X, Deng G, Hao X, Li Y, Zeng J, Ma C, He Y, Liu X, Wang Y (2014) A caspase-dependent pathway is involved in $\mathrm{Wnt} / \beta$-catenin signaling promoted apoptosis in Bacillus Calmette-Guerin infected RAW264.7 macrophages. Int J Mol Sci 15:5045-5062. CrossRef Medline

Zhang N, Wei P, Gong A, Chiu WT, Lee HT, Colman H, Huang H, Xue J, Liu M, Wang Y, Sawaya R, Xie K, Yung WK, Medema RH, He X, Huang S (2011) FoxM1 promotes $\beta$-catenin nuclear localization and controls wnt target-gene expression and glioma tumorigenesis. Cancer Cell 20:427442. CrossRef Medline

Zhao Y, Wei ZZ, Zhang JY, Zhang Y, Won S, Sun J, Yu SP, Li J, Wei L (2017) GSK-3 $\beta$ inhibition induced neuroprotection, regeneration, and functional recovery after intracerebral hemorrhagic stroke. Cell Transplant 26:395-407. CrossRef Medline 